\title{
Población en la ciudad de Campeche: fuentes y tendencias, 1810-1861
}

\author{
Carlos Alcalá Ferráez \\ Universidad Autónoma de Yucatán \\ Centro de Investigaciones Regionales Dr. Hideyo Noguchi \\ Unidad de Ciencias Sociales \\ carlos.alcala@uady.mx
}

\begin{abstract}
Resumen
El objetivo principal de este artículo consiste en el análisis de las tendencias de crecimiento de la población de la ciudad de Campeche y los factores asociados entre 1810 y 1861. Se realiza una revisión de las fuentes que registran el número de habitantes, la descripción de algunos acontecimientos que incidan en estas cifras y el comportamiento de la mortalidad, natalidad y nupcialidad durante este periodo. La población del puerto fue calculada con base en dos valoraciones. La primera entre 18000 y 20000 habitantes entre 1810 y 1833, posteriormente fue de 15000 personas. La epidemia de cólera en 1833 fue el evento que más impactó en la localidad.
\end{abstract}

Palabras clave: Campeche; censos; epidemias; crisis agrícolas; guerra civil.

\section{Population in the City of Campeche: Sources and Trends, 1810-1861}

\begin{abstract}
This article seeks principally to analyze the growth trends of the population of the city of Campeche and associated factors between 1810 and 1861. A revision was undertaken of the sources recording the number of inhabitants, the description of certain events that had an impact on these figures and the evolution of birth, death and marriage rates during this period. The population of the port was calculated using two assessments. The first was between 18000 and 20000 inhabitants between 1810 and 1833, and a later one was 15000 persons. The 1833 cholera epidemic was the event that had the greatest impact on the town.
\end{abstract}

Key words: Campeche; census; epidemics; agricultural crisis; civil war.

Fecha de recepción:

12 de julio de 2013
Fecha de aceptación:

29 de abril de 2014 


\title{
Población en la ciudad de Campeche: fuentes y tendencias, 1810-1861
}

\author{
Carlos Alcalá Ferráez
}

\section{INTRODUCCIÓN}

L os estudios de población tienen gran tradición historiográfica en Francia, gráficas del antiguo régimen y la conjugación de factores políticos, económicos, sociales y nutricionales; ${ }^{1}$ mientras que las investigaciones de Nicolás Sánchez Albornoz (1973) siguieron esta tendencia para el caso de América Latina.

Para el periodo colonial mexicano, los trabajos de Elsa Malvido (1973), Thomas Calvo (1973) y Claude Morin (1973) fueron los pioneros de esta temática y abarcaron jurisdicciones parroquiales del ámbito rural que se encontraban en el centro del país. En cuanto al sector urbano, Miguel Cuenya (1999) analizó la epidemia de matlazahuatl de 1737 en la ciudad de Puebla a través del análisis de las cinco parroquias que la conformaban. ${ }^{2}$ Para el siglo XIX, Urías y San Juan (1982, pp. 328-379) afirmaron que para un mayor conocimiento de la población mexicana se requerían estudios locales que indicasen las particulari-

\footnotetext{
${ }^{1}$ En este sentido destacaron los trabajos de Goubert (1960) y Meuvret (2003, pp. 131-140).

${ }^{2} \mathrm{Al}$ parecer fue identificada como peste bubónica. En algunos casos también fue asociada con el tifo exantemático. Véanse Cuenya (1999, p. 151) y Rabell (1990, pp. 57-67).
}

dades de una zona determinada, así como la heterogeneidad del territorio.

El objetivo de este trabajo consistirá en el análisis de los indicadores demográficos que incidieron en la población de la ciudad de Campeche entre 1810 y 1861 . En primer lugar, realizaré un balance sobre las investigaciones que se han realizado en México para el siglo XIX y en Yucatán; en segundo término describiré las condiciones de vida del puerto y sus barrios; en tercero, señalaré los principales eventos o procesos que pudieron influir en los indicadores demográficos del espacio estudiado; en cuarto, identificaré las fuentes que presenten datos sobre la población de la localidad para determinar su confiabilidad y las tendencias que señalen; en quinto, abordaré algunas generalidades con respecto a las tasas de natalidad, mortalidad y el crecimiento natural de la población campechana, y, por último, elaboraré las curvas de defunciones, matrimonios y bautizos del puerto, así como de sus barrios entre 1810 y 1861.

\section{LA POBLACión EN MÉXiCO DURANTE EL SIGLO XIX. ANTECEDENTES HISTORIOGRÁFICOS}

Victoria Lerner (1968, p. 335) y Robert Mc Caa (1993, pp. 90-113) señalaron que durante el siglo XIX las tasas de natalidad 
y mortalidad fueron elevadas, situación que provocó un crecimiento lento de la población. Esto se debió principalmente a epidemias, hambrunas, conflictos bélicos y fenómenos migratorios. Por fortuna, estas no fueron tan devastadoras como las que se presentaron durante la dominación española (Mc Caa, 1993, p. 101).

Para la ciudad de México existen dos trabajos en los que se utilizaron indicadores demográficos: en primer lugar, el de Lourdes Márquez (1994), quien a través de un estudio comparativo del brote de tifo de 1813 y el cólera de 1833 observó que la distribución y letalidad de estas enfermedades en los habitantes de la ciudad se debieron a condiciones de vida y salud heterogéneas que denominó como "la desigualdad ante la muerte" (p. 29). En segundo lugar, Celia Maldonado (1995, pp. 82-83) estableció la existencia de un patrón demográfico típico del siglo XIX en la capital del país con altos niveles de natalidad y mortalidad, así como un crecimiento natural positivo de poca cuantía, pero suficiente para sostener los volúmenes de población. Las epidemias produjeron un lento crecimiento de la población, aunque generalmente los nacimientos rebasaban a las defunciones, salvo en los años de crisis. Una vez concluidas las epidemias, las variables de población retomaban sus tendencias habituales.

En cuanto a la historiografía yucateca, la mayor parte de los trabajos se remiten a la época colonial, principalmente a la evolución del crecimiento y descenso de la población indígena, los cuales se debieron a las migraciones internas y las "calamidades" (hambres y epidemias). ${ }^{3}$ En este

\footnotetext{
${ }^{3}$ Véanse Cook y Borah (1977, t. II), Farriss (1984), García (1978) y Peniche (2010).
}

marco destacan también las investigaciones que se han realizado a través de la Red de Historia Demográfica, ${ }^{4}$ principalmente las de Alicia Contreras (2009, pp. 81-92) y Marlene Falla (2009, pp. 217-225).

Con respecto al siglo XIX, Cook y Borah (1977, t. II) afirmaron que de 1789 a 1838 existe una serie de recuentos y estimaciones que indican un incremento de la población en Yucatán. Posteriormente, la guerra de Castas tuvo efectos negativos sobre el número de habitantes en la península, pero de acuerdo con estos autores "la interrupción debe haber ocurrido algún tiempo antes, pues entre 1841 y 1846 el crecimiento había empezado a detenerse" (p. 133). Rodríguez Losa (1985, t. I) realizó una breve revisión sobre los censos de Yucatán entre 1772 y 1846 y afirmó que "por la relación de censos o estados de población mencionados, se puede decir que la mayor parte de ellos son cálculos y no se ha explicado el proceso que se siguió para obtener los totales presentados" (p. 21). En este sentido, una de mis contribuciones consiste en la realización de un estudio de la evolución de las cifras y del crecimiento natural de la población en la ciudad de Campeche, así como sus factores asociados. En este sentido, en el siguiente apartado describiré el espacio de estudio.

${ }^{4}$ La Red de Historia Demográfica se fundó el 1 de diciembre de 2009 con investigadores de la Universidad Autónoma de Baja Californian (UABC), Universidad Autónoma del Estado de México (UAEM), Universidad Veracruzana (UV), Universidad Autónoma de Yucatán (UADY), Universidad de Guadalajara (U de G), Escuela Nacional de Antropología e Historia (ENAH) y El Colegio de Michoacán (COLMICH), y desde entonces ha organizado coloquios y seminarios cuyos resultados están plasmados en publicaciones colectivas. Actualmente cuenta con 26 integrantes. 
EL ESPACIO DE ESTUDIO: LA CIUDAD DE CAMPECHE

Campeche ${ }^{5}$ se encuentra al oeste de la península de Yucatán y durante el periodo que abarca la presente investigación fue uno de los principales puertos de cabotaje en el Golfo de México. ${ }^{6}$ Contaba con un recinto amurallado que, junto con los barrios de Guadalupe, San Román y Santa Ana, formaron parte de la parroquia del Sagrario, mientras que la de San Francisco abarcaba el suburbio del mismo nombre y el de Santa Lucía. ${ }^{7}$

Las calles eran angostas e irregulares con pavimento natural de piedra lisa, que producía trazados irregulares para los carruajes (Norman, 1843, p. 114). En el

\footnotetext{
${ }^{5}$ Para una mayor explicación de las condiciones urbanas de las ciudades en México, durante la primera mitad del siglo XIX, véanse Cuenya y Malvido (1992, pp. 11-45), Maldonado (1995), Márquez (1994) y Oliver (1986).

${ }^{6}$ Con respecto a los puertos del Golfo de México y su actividad durante el siglo XIX, véanse Muñoz (2006, t. I, pp. 469-514) y Trujillo (2005).

${ }^{7}$ De manera más específica, conviene mencionar que durante el régimen borbónico, el virreinato de la Nueva España se dividió en dos provincias internas, doce intendencias y tres gobiernos. Con respecto a las intendencias, la de Mérida formaba parte de la península de Yucatán, la cual se dividía en partidos. En este caso, el puerto de Campeche perteneció al partido del mismo nombre. Entre 1821 y 1861, la división del territorio mexicano se realizó de acuerdo con el sistema de gobierno federal o central, es decir, en estados o departamentos, respectivamente. Durante el sistema federal, Yucatán mantuvo el sistema de partidos, mientras que durante el régimen centralista, estos se agruparon en distritos y el correspondiente a Campeche se convirtió en estado de la federación en 1863. Para la división territorial de la república mexicana y Yucatán véanse O’ Gorman (1966) y Rodríguez (1989), respectivamente.
}

muelle se encontraba la pescadería y se efectuaban las actividades mercantiles; sin embargo, no podían atracar grandes embarcaciones, las cuales permanecían a cierta distancia del puerto o anclaban en un sitio conocido como el Pozo (Regil, 1853, p. 108).

La plaza principal era un gran espacio vacío en el que se realizaban las principales ceremonias religiosas, políticas, militares y sociales. Alrededor se encontraban los edificios de las principales instituciones de gobierno y La Lonja Campechana, que según Heller era un sitio "mantenido por suscripciones de los habitantes ricos" (Heller, 1987, p. 191). Los sábados se observaban mendigos indígenas que se instalaban alrededor y recibían limosnas por parte de los habitantes (Norman, 1843, pp. 210-211). En el recinto se encontraban otras iglesias, el hospital San Juan de Dios, el colegio de San Miguel de Estrada y el teatro Toro. ${ }^{8}$

De acuerdo con el censo de 1810 las personas de la plaza se dedicaban a trabajos relacionados con la administración pública y el comercio. Destacaba la existencia de seis médicos y un boticario para el ramo de salud, así como el predominio de empleados militares debido a la importancia que el puerto tenía como sitio de defensa.? En 1844 predominaban militares, comerciantes, tenderos, sastres, plateros, empleados administrativos y boticarios. ${ }^{10}$

${ }^{8}$ Para descripción más detallada de la ciudad de Campeche y sus barrios véase Alcalá (2010, pp. 201-244).

${ }_{9}^{9}$ Censo de población con manifestaciones de castas, clases y su distribución en barrios. Campeche. 1810. Apartado colonial. Censos y padrones. Vol. 2, exp. 1. Archivo General del Estado de Yucatán (AGEY), México.

${ }^{10}$ Padrón de los individuos que habitan en la primera sección de la ciudad de Campeche. 1844. 
El barrio de Guadalupe surgió como consecuencia de la fortificación que excluyó algunas cuadras que componían el primer cuadro del puerto. La población estaba conformada por españoles y criollos, quienes en su mayoría eran artesanos y jornaleros. ${ }^{11}$ El barrio de San Román se encontraba al oeste del recinto amurallado $^{12}$ y sus habitantes trabajaban principalmente en los astilleros de la industria naval, pero también existían militares, jornaleros, artesanos y algunos comerciantes. ${ }^{13}$ En esta zona se encontraban el cementerio general y el hospital de San Lázaro.

El barrio de Santa Ana se ubicaba al sur de la zona fortificada y la mayor parte de sus moradores se dedicaba a la labranza, aunque también se reportaron jornaleros, artesanos, albañiles, recolectores de basura y zapateros. ${ }^{14}$ En San Francisco la actividad principal era la pesca, pero hacia el interior existían hortalizas donde se cultivaba el maíz. También se encontraban artesanos, militares, labradores e, incluso, los padrones reportaron la presencia de médicos y algunos comer-

Administración pública. Caja 5, exp. 245. Archivo Municipal de Campeche (AMC), México.

${ }^{11}$ Censo de población con manifestaciones de castas, clases y su distribución en barrios. Campeche. 1810. Apartado colonial. Censos y padrones. Vol. 2, exp. 1. AGEY, México.

${ }^{12}$ Un trabajo interesante sobre el barrio de San Román es el de Aguayo y Cahuich (1997).

${ }^{13}$ Censo de población con manifestaciones de castas, clases y su distribución en barrios. Campeche. 1810. Apartado colonial. Censos y padrones. Vol. 2, exp. 1. AGEY, México.

${ }^{14}$ Censo de población con manifestaciones de castas, clases y su distribución en barrios. Campeche. 1810. Apartado colonial. Censos y padrones. Vol. 2, exp. 1. AGEY, México. ciantes. ${ }^{15}$ En esta zona se encontraba el estero conocido como La Ría, un desagüe natural de la ciudad. Santa Lucía fue el último suburbio en desarrollarse y concentraba población indígena que se dedicaba a la milicia, a la labranza y a la elaboración de artesanías. ${ }^{16}$

Según Heller (1987), en 1847 las personas del recinto amuralladas eran tan cultas y educadas que podían compararse a las correspondientes en Europa. Los hombres vestían con levita corta y bombín, frac o chaqueta y sombrero de copa, chaleco, camisa, corbata y botines (p. 191). Los que ejercían algún oficio utilizaban pantalones anchos de color blanco, una camisa de lino planchada; al costado portaban un machete en forma de clava y cubrían la cabeza con un sombrero de palma. Las mujeres portaban vestidos bajos y mangas cortas, con un pañuelo alrededor del cuello, así como un ligero chal sobre los hombros (Parrish, 1853, p. 163).

La vestimenta de los hombres indígenas consistía en un pantalón ancho y corto que llegaba a la mitad de la pierna, aunque normalmente lo tenían arrollado a la altura de los muslos (Waldeck, 1996, p. 70). Las mujeres mayas empleaban una falda (fustán) que le llegaba a los tobillos y encima una camisa blanca (buipil), cuyo borde estaba adornado con flores. El calzado consistía en zapatos de seda o sandalias de cuero (Heller, 1987, p. 192). El

${ }^{15}$ Censo de población con manifestaciones de castas, clases y su distribución en barrios. Campeche. 1810. Apartado colonial. Censos y padrones. Vol. 2, exp. 1. AGEY. México.

${ }^{16}$ Censo de población con manifestaciones de castas, clases y su distribución en barrios. Campeche. 1810. Apartado colonial. Censos y padrones. Vol. 2, exp. 1. AGEY. México. 
tipo de vivienda se distinguía de acuerdo con el nivel ocupado en la escala social. Las casas de la clase acomodada se componían de dos plantas: la planta baja se empleaba para actividades laborales (Waldeck, 1996, p. 71), mientras que en el segundo nivel se encontraba la casa habitación. Las casas más humildes se construían en forma oblonga, con postes verticales clavados en el suelo sosteniendo la cubierta. Eran de una planta con techos de palma o guano, tenían huertos frutales y estaban rodeadas con cercas de piedra.

El agua que se utilizaba para el consumo humano se obtenía de las lluvias y se almacenaba en cisternas o aljibes. En Campeche, los pozos ubicados fuera del recinto Belén y El Mamey suministraban agua a los aljibes particulares ( $\mathrm{Ra}-$ mos, 1875, pp. 186-192). También se vendía en las calles y era transportada en carretas (Waldeck, 1996, p. 72). Sin embargo, estos carecían de protección sanitaria, lo cual constituía un factor de riesgo para la morbilidad de los padecimientos gastrointestinales.

La alimentación de la gente que vivía en el recinto consistía en peces y mariscos, así como carnes de res, ave y cerdo, acompañada de salsas o aderezos, mientras que el maíz era la base dietética de los indígenas (Waldeck, 1996, p. 73). La venta de comestibles se realizaba en el muelle, la plaza principal y el mercado. El principal producto de la pescadería era un tiburón pequeño conocido como cazón, abundante y barato, que se cocinaba como platillo principal en la mesa de los hogares campechanos (Morelet, 1871, p. 22).

Desde el periodo colonial, los servicios públicos estuvieron encomendados a los municipios, aspecto que se reforzó en la Constitución de Cádiz y los proyectos de reforma de la Constitución centralista de $1836 .{ }^{17}$ El Ayuntamiento de la ciudad de Campeche proporcionaba servicios básicos con respecto a la limpieza y arreglo de calles, recolección de basura y obra pública enfocada al manejo de las aguas negras, como las del mercado cercano a la plaza principal, el rastro público del barrio de San Francisco y la entrada del barrio de Santa Ana que en época de lluvias se inundaba. Sin embargo, esto no impidió que las condiciones de salubridad urbana y la falta de higiene se convirtieran en factores predisponentes para diversas enfermedades.

Con respecto al mercado, en 1818 se autorizó la construcción de una galera que sirviera como bodega para los utensilios de los trabajadores, pero era necesario remodelar las demás instalaciones debido al mal estado en que se encontraban (Álvarez, 1912, t. I, p. 87). Estas se encontraban guarnecidas por portales de piedra, pero los puestos de frutas, legumbres y granos no tenían techo.

Para la recolección de basura existían carretones para el aseo de las calles de la ciudad y mediante una campanilla se avisaba a la gente para que depositaran sus desechos en las esquinas (Álvarez, 1912,

17 “Art. 150. Los ayuntamientos se renovarán por tercios cada dos años, y estará a cargo de ellos en sus demarcaciones respectivas: la policía de salubridad, comodidad y ornato: el cuidado de las cárceles, de los hospitales y las casas de beneficencia, que no sean de fundación particular; de las escuelas de primera enseñanza, que se paguen de los fondos del común: de la construcción y reparación de puentes, calzadas y caminos: de la recaudación e inversión de los propios y arbitrios: finalmente, promover el adelantamiento de la agricultura, industria y comercio; todo con absoluta sujeción a las leyes y reglamentos." (Tena, 1999, p. 284). 
t. I, p. 131). En 1850, ante las noticias de que el cólera afectaba la villa de $\mathrm{Pa}$ lizada, se incrementó la cantidad de estos: "Ya que habiendo acordado que las basuras que se recogen en la ciudad se arrogen [sic] á cierta distancia fuera de la población, con el objeto de que no perjudiquen á la salud pública."18

El mar era un vertedero de desechos como lo demuestra, en primer lugar, la construcción de cuatro caños subterráneos en el matadero de abasto público del barrio de San Francisco: "con el fin de evitar la fetidez tan insufrible que padece el vecindario". ${ }^{19}$ En segundo lugar, la excavación del caño de desagüe del mercado ${ }^{20}$ debido a las inundaciones que "desde la esquina del principal hasta las galerías de los abastecedores públicos", ${ }^{21}$ sufría la ciudad durante la temporada de lluvias.

En 1830 se construyó un canal para desagüe en el barrio de Santa Ana debido a los perjuicios que ocasionaba el estancamiento de agua junto con las "materias

\footnotetext{
${ }^{18}$ Notificación de los presupuestos para la construcción de dos carros para la limpieza pública. 1850. Periodo yucateco. Caja 12, exp. 943. Archivo General del Estado de Campeche (AGEC), México.

${ }^{19} \mathrm{El}$ mal olor era sinónimo de contaminación y de acuerdo con la teoría miasmática se convertía en factor de riesgo para contraer enfermedades. Presupuesto para la reparación del matadero del abasto público, situado a espalda del convento de San Francisco. 1844. Obras públicas. Caja 4, exp. 182. AMC, México.

${ }^{20}$ Autorización de la solicitud del Ayuntamiento de Campeche para la reparación del desagüe, la casa de la municipalidad y del hospital de San Juan de Dios. 1844. Periodo yucateco. Caja 2, exp. 127. AGEC, México.

${ }^{21}$ Presupuesto para la excavación del caño de desagüe del mercado público. 1844. Obras públicas. Caja 4, exp. 19. AMC, México.
}

fétidas y corruptibles causando mucho daño a la salubridad pública" (Álvarez, 1912 , t. I, p. 223), pero no recibió el mantenimiento adecuado (p. 375). Posteriormente se construyó el puente de Iturbide en la calle principal del barrio: "por ser un lugar en el que afluyendo varias corrientes, se convierte en un lago, haciéndolo completamente intransitable, en la estación de las lluvias orientales" (p. 387).

\section{¿COYUNTURAS DE CRISIS?}

El siguiente paso consistirá en la descripción de eventos que pudieran alterar las variables de población en la península de Yucatán y la ciudad de Campeche. En el texto destacaré la información proporcionada por nuestras fuentes en relación con el puerto campechano. En otros lugares estos acontecimientos produjeron crisis demográficas, entendiéndose estas como "un conjunto de sucesos demográficos que se sitúan en el corto periodo de ensamblaje entre un movimiento ascendente y otro de declive de la población" (Pérez, 1980, pp. 58-59).

En primer lugar consulté la información relacionada con crisis alimentarias destacando los catálogos publicados por el Centro de Investigaciones y Estudios Superiores en Antropología Social (CIESAS). $\mathrm{Al}$ respecto, cabe mencionar que las publicaciones relacionadas con Yucatán han abordado el periodo colonial, situación que abre nuevas ventanas de investigación para el análisis de estos fenómenos, porque estos continuaron afectando a la zona, tal como puede observarse en el cuadro 1. Para la ciudad de Campeche, el catálogo de Escobar Ohmstede (2004, t. II) mencionó que en septiembre de 1850: 


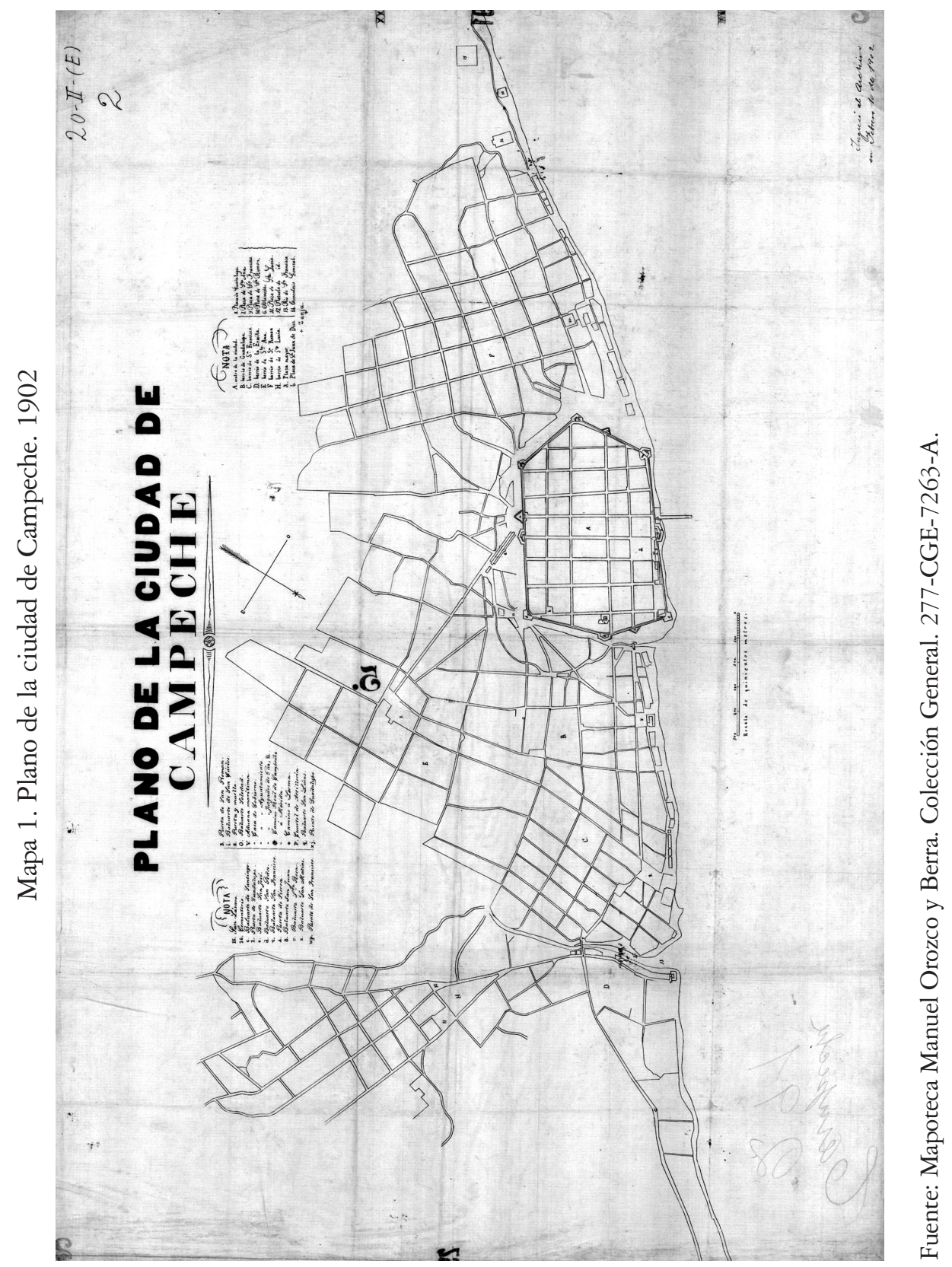

\section{(ㅇ)(1) $(2)$}


Cuadro 1. Eventos relacionados con posibles crisis demográficas en la península de Yucatán y la ciudad de Campeche

$A \tilde{n} o$

1810 Yucatán: hambruna, epidemia, crisis.

1813 Yucatán: epidemias de fiebres y sequías.

1817 Yucatán: hambre, pérdida de cosechas, falta de lluvia y traslado de la población.

1822 Yucatán: escasez de lluvias.

1823 Yucatán: escasez, hambre, pérdida de cosechas y sequías.

1826 Yucatán: lluvias abundantes y escasez de granos.

Ciudad de Campeche: epidemia de viruela.

1827 Yucatán: escasez de granos.

1831 Yucatán: plaga.

1833 Ciudad de Campeche: epidemia de cólera.

1834 Yucatán: sequía y escasez de granos.

1835 Yucatán: escasez de granos.

Yucatán: escasez de lluvia. El Rancho Santa Rosa fue de los sitios más afectados.

1840 La ciudad de Campeche fue sitiada por las tropas federalistas durante el mes de junio.

1842 Yucatán: escasez de lluvia y carestía.

1843 Asedio del ejército mexicano en la ciudad de Campeche.

1847 Yucatán: guerra de Castas.

1848 Ciudad de Campeche: guerra de Castas.

1849 Yucatán: guerra de Castas. Yucatán: escasez de granos.

1850 Ciudad de Campeche y Yucatán: escasez de granos.
Fuente

García, Pérez y Molina (2003, t. I, p. 448).

García, Pérez y Molina (2003, t. I, p. 450).

García, Pérez y Molina (2003, t. I, pp. 454-455).

Molina (1941, p. 27).

Escobar (2004, t. II, p. 49).

Molina (1941, pp. 28-29).

García, Pérez y Molina (2003, t. I, pp. 456-457).

Molina (1941, pp. 28-29).

Escobar (2004, t. II, p. 50).

Alcalá (2008, pp. 172-187).

Escobar (2004, t. II, p. 50).

Escobar (2004, t. II, p. 56).

Alcalá (2008, pp. 188-213).

Escobar (2004, t. II, p. 57).

Castillo (2002, pp. 213-228).

Molina (1941, p. 29).

Escobar (2004, t. II, 57).

Castillo (2002, pp. 213-228).

Molina (1941, p. 29).

Escobar (2004, t. II, p. 57).

Stephens (1986, t. II, pp. 138-141).

Campos (2002, p. 130).

Escobar (2004, t. II, p. 61).

Negrín (1991, p. 53).

Cline (1945), Reed (1985).

Álvarez (1912, t. I, pp. 413-414).

Cline (1945), Reed (1985).

Escobar (2004, t. II, pp. 67-69).

Escobar (2004, t. II, p. 69). 
1853

Ciudad de Campeche: epidemia de cólera.

1855

Ciudad de Campeche: epidemia de viruela.

1857

La ciudad de Campeche fue rodeada por el ejército de Yucatán entre los meses de septiembre y enero de 1858 .
"En los cantones avanzados del sur y del oriente reinaba una terrible escasez de granos. En el mismo mercado de Campeche se había notado una escasez extraordinaria de maíz" (p. 64).

Con respecto a las epidemias revisé colecciones generales como la Enciclopedia yucatanense (1944) y los Anales históricos de Campeche (Álvarez, 1912), así como también los trabajos de Pedro de Regil (1853), Justo Sierra O’ Reilly (1991), y la Monografía sobre salud pública en Yucatán (Erosa, 1993). Los resultados de esta búsqueda reportaron que las epidemias de viruela en 1826 y 1855, así como la de cólera de 1833 y 1853 fueron las enfermedades que más afectaron a la península durante este periodo.

En relación con la viruela en Campeche, el 10 de marzo de 1826, el Ayuntamiento declaró la ciudad en estado epidémico. Se ordenó la habilitación del hospital San Lázaro, se solicitó que los facultativos propagaran la vacuna y se notificó a los comisarios de los cuarteles ${ }^{22}$ para que elaboraran una lista de las personas no vacunadas; esto para obligarlos a recibir el suero. También se determinó que las personas que no reportaran a los enfermos serían multadas o encarceladas (Álvarez, 1912, t. I, pp. 185-186).

\footnotetext{
${ }^{22}$ Respecto a los cuarteles de la ciudad de Campeche, véase Arjona (2007).
}

Alcalá (2008, pp. 188-213).

Alcalá (2008, pp. 172-187).

Negrín (1991, p. 69).

Para el segundo brote, el 30 de noviembre de 1854 se reportaron casos de viruela. El Ayuntamiento comisionó a los regidores Julián Gual y Lucas Molina para abrir nuevamente el Lazareto y conducir a los virulentos. El 7 de diciembre, la comisión anunció que el hospital estaba en funciones, pero durante los meses de marzo y junio de 1855 se presentaron los estragos mayores de esta epidemia, hasta que el 12 de noviembre se reportó el último caso (Álvarez, 1912, t. I, pp. 495-496).

En cuanto al cólera, el 26 de noviembre de 1832 se informó que la epidemia había atacado Nueva Orleans y se constituyó la Comisión Permanente Facultativa de Sanidad (Álvarez, 1912, t. I, p. 244). Este organismo dictó medidas preventivas encaminadas al aseo y limpieza de la ciudad, así como la obtención de fondos a través del gobierno estatal y la creación de una Junta de Auxilios (pp. 252-253). Pero el 21 de junio ${ }^{23}$ se registró el primer enfermo y la Junta de Sanidad dispuso el traslado de los enfermos a los hospitales que se habilitaron, así como la contratación de médicos que atendieran dichos establecimientos. El Ayuntamiento ordenó que las boticas despachasen las recetas para gente sin recursos, sin ningún costo, y el

${ }^{23}$ El Baluarte de la Libertad, 6 de julio de 1833 , núm. 94, p. 1, Mérida. 
22 de julio se declaró el fin de la enfermedad (pp. 254-255).

En Yucatán, un levantamiento armado contra el gobierno estatal sitió la ciudad de Mérida del 27 de septiembre al 4 de octubre de 1853. Los rebeldes fueron derrotados, pero en sus filas contaban con gente infectada de cólera que propagó la enfermedad hacia el resto de la península (Laviada, 1993, p. 46). El 13 de octubre, el Ayuntamiento de Campeche contrató médicos para que atendieran a los enfermos. El 27 de ese mes se reportaron algunos casos, los cuales se incrementaron y se habilitó un hospital en el barrio de San Francisco. El 2 de noviembre la ciudad fue declarada en estado epidémico hasta octubre del siguiente año (Álvarez, 1912, t. I, pp. 475-476). En ese periodo, se modificó la fecha de la festividad del Cristo Negro del barrio de San Román, debido a que el obispo, cuya sede se encontraba en Mérida, no podía trasladarse al puerto. ${ }^{24}$

Entre los conflictos bélicos, la guerra de Castas fue el acontecimiento de mayor trascendencia en la península de Yucatán. ${ }^{25}$ El 30 de julio de 1847 los indios mayas se levantaron en armas contra la población blanca y tomaron las poblaciones tanto del sur, como del oriente del estado (Reed, 1985, pp. 61-81). El 19 de abril de 1848 se firmaron los convenios de Tzucacab, pero los sectores radicales del movimiento no reconocieron estos

${ }^{24}$ El Orden. Periódico Oficial, 27 de octubre de 1854, núm. 111, p. 3, Campeche.

${ }^{25}$ Para conocer los aspectos fundamentales, véanse los trabajos clásicos de Berzunza (1965), Reed (1985) y Cline (1945). Para el caso de Campeche, véase Ramayo (1996). De los trabajos recientes destacan los de Dumond (2005) y Villalobos (2006). acuerdos (pp. 94-95). En efecto, ante la división de los líderes del movimiento, las tropas del gobierno recuperaron gran parte del territorio, mientras que los rebeldes fundaron Chan Santa Cruz, ${ }^{26}$ poblado donde se refugiaron hasta 1901 (p. 131).

La población afectada huyó de la zona de conflicto y en 1848 el puerto se convirtió en uno de los principales refugios. Los sublevados se acercaron a las inmediaciones del recinto amurallado, pero fueron rechazados. Los caminos estaban totalmente destruidos, agujerados por trincheras, obstaculizadas por albarradas y árboles gigantescos, así como los pozos envenenados o rellenados para evitar el consumo de agua. En consecuencia, la ciudad se vio afectada por la escasez de productos básicos, la falta de espacio, el hacinamiento de asentamientos provisionales y la amenaza de epidemias. Como medidas a esta situación, las autoridades dispusieron que el hospital San Lázaro funcionara como albergue y se construyó un nuevo cementerio (Ramayo, 1996, pp. 206-217).

\section{LAS CIFRAS DE POBLACIÓN}

El objetivo principal de este apartado consiste en el registro de las cifras de población del puerto campechano. Se revisaron los textos de Cook y Borah (1977, t. II), de Ignacio Rubio Mañé (1942) y de Pablo Pérez-Mallaína (1978) porque proporcionaron las fuentes consultadas durante sus investigaciones. Asimismo, consultamos algunos informes estadísticos correspondientes a la primera mitad del siglo XIX y

${ }^{26}$ Actualmente es la ciudad de Felipe Carrillo Puerto, en el estado de Quintana Roo. 
que analizan aspectos demográficos de la península yucateca. ${ }^{27}$ En cuanto a los censos encontramos los de 1810, 1814 y 1861. Además, el legajo de Padrones, Estadísticas y Censos del Archivo Histórico de la Diócesis de Campeche contiene reportes del número de habitantes por parroquia.

A finales del siglo XVIII, y dentro del marco de las reformas borbónicas, se realizaron los primeros censos en la península de Yucatán. En principio, las Ordenanzas de Intendentes de la Nueva España decretaron la elaboración de censos quinquenales, pero después de 1794 no se realizaron periódicamente (Pérez-Mallaína, 1978, p. 22). Con respecto a la ciudad de Campeche, se reportaron 16940 habitantes durante ese año (Rubio, 1942).

En relación con nuestro periodo de estudio tenemos que ubicar nuestros primeros datos en las postrimerías del periodo colonial (véase cuadro 2). En 1809, Benito Pérez Valdelomar recibió la orden de levantar el padrón correspondiente para todo el territorio. En el documento resalta el contexto de la época con respecto a la ocupación francesa en España y la necesidad de contar con efectivos militares:

y por cuanto en debido cumplimiento de sabernos justos y piadosos y disposiciones del rey, he determinado que a la mayor posibilidad brevedad se forme el padrón más exacto de los vecindarios españoles, castizos, mestizos, negros y pardos de toda esta provincia, dando principio por los que son vecinos de esta capital, sus barrios, haciendas y ranchos de su jurisdicción y pueblos dependientes de la misma. [...] para saber el

${ }^{27}$ Principalmente los que se publicaron en 1814 , 1846,1853 y 1861. número fijo de los hombres útiles que existen en esta capital y sus dependientes para defender en los casos urgentes de religión, la patria, el dominio del soberano y los sagrados derechos de la nación insultada en el día por el mayor monstruo de la tiranía, asegurando también para lo sucesivo la continuación de noticias exactas de padrones para el completo anual de milicias [...] no creo que ningún vecino sea de la clase que fuere ocultara su nombre, calidad, edad, ejercicio y número circunstanciado de su familia al comisionado. $^{28}$

El documento consideró a todos los grupos de edad. Se calculó por sexo, solteros, casados y viudos, así como la distribución por castas conformadas por europeos, españoles y mulatos. También existía una relación de los oficios desempeñados y se contaba a los indígenas con las mismas variables. Campeche reportó un total de 19834 habitantes, sin considerar la población indígena del barrio de Guadalupe, por lo que la estimación fue incompleta. Vale la pena decir que una causa del subregistro se debió a la población masculina mayor de catorce años, quienes tenían que pagar tributo y enrolarse a la milicia; en consecuencia, escapaban hacia las zonas despobladas de la península. ${ }^{29}$ También, las autoridades alteraron los resultados para obtener mayor representación en las Cortes (Rodríguez, 1985, t. I, p. 17).

${ }^{28}$ Mandamiento a don Benito Pérez Valdelomar, gobernador de Yucatán, en que se ordena se haga el padrón en esa provincia. 3 de agosto de 1809. Colonial. Bandos y ordenanzas. Vol. 1, exp. 7. AGEY, México.

${ }^{29}$ La mayor parte de esta población era indígena. Con respecto a los mecanismos de huida, véase Farriss (1984). 


\section{Cuadro 2. Población de la ciudad de Campeche, 1810-1861}

\begin{tabular}{|c|c|c|}
\hline Añ & Población & Fuente \\
\hline 1810 & 19834 & $\begin{array}{l}\text { Censo de población con manifestaciones de castas, clases y su distribución } \\
\text { en barrios. Campeche. 1810. Apartado Colonial. Censos y padrones. Vol. 2, } \\
\text { exp. 1. AGEY, México. }\end{array}$ \\
\hline 1813 & 17390 & $\begin{array}{l}\text { Legajo de padrones, estadísticas y censos. 1808-1924. Caja 217. AHDC, } \\
\text { México. }\end{array}$ \\
\hline 1814 & 19638 & Echánove (1814, p. 46). \\
\hline 1821 & 18310 & Rodríguez (1985, cuadro IX). \\
\hline 1829 & 17400 & $\begin{array}{l}\text { Legajo de padrones, estadísticas y censos. 1808-1924. Caja 217. AHDC, } \\
\text { México. No incluye la parroquia de San Francisco extramuros. }\end{array}$ \\
\hline 833 & 16805 & $\begin{array}{l}\text { Legajo de padrones, estadísticas y censos. 1808-1924. Caja 217. AHDC. } \\
\text { México. }\end{array}$ \\
\hline 1840 & 15900 & $\begin{array}{l}\text { Legajo de padrones, estadísticas y censos. 1808-1924. Caja 217. AHDC, } \\
\text { México. }\end{array}$ \\
\hline 1843 & 15000 & Norman (1843, p. 210$)$ \\
\hline 1846 & 15347 & $\begin{array}{l}\text { "Nómina alfabética de las ciudades, villas y pueblos de la península de } \\
\text { Yucatán, con expresión de la distancia a que se hallan de la capital. El } \\
\text { partido y distrito a que corresponden, y número de habitantes en cada uno. } \\
\text { Los que son cabecera de curato son marcados con la letra C". Elaborada en } \\
1846 \text { por el secretario de Gobierno de Yucatán, Joaquín García Rejón. } \\
\text { Fondo: Héctor Pérez Martínez. Biblioteca Campeche. }\end{array}$ \\
\hline 1849 & 12000 a 13000 & $\begin{array}{l}\text { Sierra (1975, p. 56) cita a Gondra, Isidro; Campeche. El Álbum Mexicano, } \\
\text { periódico de literatura, artes y bellas letras (t. I). México: Publicado por } \\
\text { Ignacio Cumplido, t. I, } 1849 \text {. }\end{array}$ \\
\hline & 15357 & Parrish (1853, p. 145). \\
\hline & 15000 & Regil (1853, p. 106). \\
\hline & 15197 & Aznar y Carbó (1861,pp. 176-177). \\
\hline
\end{tabular}

Para 1814 existen dos recuentos: el primero fue de 19638 personas y se reportó, por un lado, en el Cuadro estadístico de Yucatán en 1814 (Echánove, 1814), y por otro, en las Apuntaciones para la estadística de la provincia de Yucatán (Calzadilla, Bolio y Zuaznávar, 1977). La segunda cantidad fue de 17390 habitantes y proviene del censo que se levantó según lo estipulado en la Constitución de Cádiz. ${ }^{30} \mathrm{La}$ fuente incluyó todos los barrios, el número de casas y dividió a los habitantes de

${ }^{30}$ Legajo de Padrones, estadísticas y censos. 1808-1924. Caja 217. Archivo Histórico de la Diócesis de Campeche (AHDC). 
acuerdo con la condición del ciudadano. ${ }^{31}$ En cuanto a la edad, no se contaron a los menores de un año y a las mujeres mayores de 60 .

El siguiente dato correspondió al 7 de marzo de 1829, en el documento intitulado Razón del número de pueblos de que se compone el curato de Campeche, su población, su número de leguas, excelentísimos que lo administran, productos y demás circunstancias que se previenen en suprema orden de 8 de noviembre último, en virtud de la cual lo presenta su párroco cura José Mariano de Cicero. En este reporte se contabilizaron 17400 habitantes que correspondían a la parroquia del Sagrario, pero no se presentaron datos para la de San Francisco Extramuros. Como se puede leer en la fuente, era un informe sobre gastos realizados en el curato. $^{32}$

Después de la epidemia del cólera de 1833, algunos expedientes del Archivo Municipal mencionaron que antes de esta enfermedad, el puerto contaba con 20000 personas y posteriormente con 15000 . Esta información fue tomada del cuadro estadístico de las víctimas de la enfermedad. En el correspondiente a Campeche, la

${ }^{31}$ Esta se promulgó en 1812. De acuerdo al artículo 1: "la nación española es la reunión de todos los españoles de ambos hemisferios" (Tena, 1999, p. 60). El ciudadano tiene residencia, derechos civiles como la propiedad y la libertad, así como derechos políticos, destacando la capacidad de elegir a sus representantes. De acuerdo con este planteamiento. Son excluidos como ciudadanos los esclavos y los extranjeros transeúntes. Los menores de 21 años, las mujeres, los extranjeros y las castas no tenían derechos políticos. Véase Guerra (1999, pp. 43-44). Para la cuestión del ciudadano en Yucatán, véase Campos (2006).

${ }^{32}$ Legajo de Padrones, estadísticas y censos. 1808-1924. Caja 217. AHDC. población se redujo a 16805 habitantes, ${ }^{33}$ la cual es más confiable y denota que esta fue redondeada en la documentación oficial (Álvarez, 1912, t. I, p. 256). En 1840, el obispado de Yucatán solicitó al curato de Campeche ${ }^{34}$ el número de almas que conformaban el lugar. ${ }^{35}$ En el reporte se enumeraron 15900 habitantes para la ciudad.

A partir de 1833 podemos observar que las estimaciones para la ciudad de Campeche tomaron como referencia la cifra de 15000 habitantes. La dificultad para realizar censos con mayor precisión fue explicada en la Memoria leída ante el Augusto Congreso Extraordinario de Yucatán por el secretario general de Gobierno, el día 18 de septiembre de 1846. En la introducción de este documento, Joaquín García Rejón indicó que la población aumentó en la península porque no se habían presentado: "epidemia desoladoras y aún de enfermedades agudas que disminuyen, devastan y arruinan a los pueblos" (García, 1846, p. 6). Sin embargo, no mencionó cuándo desaparecieron estos padecimientos.

La falta de censos destacaba la necesidad de realizar cómputos "con el convencimiento y la precisión que se desea" (García, 1846, p. 7). Al respecto se pidieron informes a los partidos que compo-

${ }^{33}$ Legajo relativo a Salud Pública. 1809-1962. Caja 219. AHDC.

${ }^{34}$ Se refiere a las parroquias del Sagrario y San Francisco Extramuros.

${ }^{35}$ Durante el periodo colonial los seres humanos estuvieron compuestos por dos entidades, el cuerpo que era responsabilidad civil y el alma de la Iglesia católica. Esta se obtenía a través del bautismo (Malvido, 2006, p. 50). En los censos no se usa este término para referirse al número de habitantes; sin embargo, la Iglesia católica lo utilizó para referirse al número de feligreses. 
nían el territorio yucateco, ${ }^{36}$ pero García Rejón (1846) mencionó que

Este censo, por más cuidado que se haya puesto en su formación, no puede considerarse que sea exacto; semejantes operaciones se practican siempre por las noticias que se piden, y estas comúnmente se dan haciendo ocultaciones (p. 7).

Una manera de realizar el cálculo era a través de las matrículas de los contribuyentes que se encontraban en la Tesorería General. Se determinó que por cada matriculado existía una familia compuesta de cinco personas. De este documento se desprende la Nómina alfabética de ciudades, villas y pueblos de la península de Yucatán, con expresión de la distancia a que se ballan de la capital, el partido y el distrito a que corresponde y número de babitantes de cada uno. Los que son cabeceras de curato están marcados con la letra $C$. La valoración para Campeche fue de 15347 personas en 1846.

En 1853, dos escritos mencionaron la misma tendencia poblacional del puerto y las causas de su decadencia. José María Regil (1853) afirmó en la Estadística de Yucatán que la ciudad "apenas logra mantenerse hoy lánguidamente en su antiguo rango de que visible y rápidamente decae" (p. 109). Igualmente, el político e intelectual yucateco Justo Sierra O' Reilly (1991) mencionó:

Su población actual puede calcularse en 15000 habitantes, sin embargo, de haber ascendido a 22000 antes de la horrible in-

${ }^{36}$ En 1846 la división política de Yucatán constaba de cinco distritos y 18 partidos. Campeche se encontraba en el distrito y el partido del mismo nombre (Rodríguez, 1989, t. II, pp. 92-101). vasión del cólera asiático en 1833 que le arrancó un tercio de sus habitantes, porque ha sido seguramente uno de los puntos en que la fatal epidemia se cebó con más saña. En estos últimos tiempos, en que el servicio militar que exigían las circunstancias de la guerra con los bárbaros obligaba a multitud de menesterales a abandonar sus talleres, el hogar doméstico y su honesto modo de vivir para ir a luchar sin paga, sin recompensa y sin gloria, con un enemigo brutal, incasable y perpetuamente en pie para destruir todas las combinaciones, en estos tiempos de crisis incesantes, la población de Campeche que comenzaba a reponerse del contratiempo de 1833 ha disminuido considerablemente: la emigración ha sido notable y lo están probando el sinnúmero de casas abandonadas y desiertas que se ven intramuros, y los eriazos de los arrabales (pp. 28-29).

El censo de 1861 se encuentra en el documento que Tomás Aznar Barbachano y Juan Carbó (1861) presentaron ante el Congreso de la Unión para justificar la creación del estado de Campeche. ${ }^{37}$ Los autores fueron dos personajes importantes en el medio cultural, periodístico y político de la península de Yucatán (Rodríguez, 2010, pp. 10-12). La naciente entidad federativa no tenía el reconocimiento legal del gobierno nacional, ya que se había separado de Yucatán desde el 3 de mayo de 1858 y

${ }^{37}$ Memoria sobre la conveniencia, utilidad y necesidad de erigir constitucionalmente en estado de la confederación mexicana el antiguo distrito de Campeche. Constituido de becho en Estado Libre y Soberano desde mayo de 1848 por virtud de los convenios de división territorial que celebró con el estado de Yucatán, de que era parte. Al respecto véase Rodríguez (2010). 
requería la aprobación de los diputados federales. $^{38}$

La ciudad registró 15197 habitantes, los datos del censo distribuyeron a la población por barrios, sexo y edad. Este último se conjuntó en grupos quinquenales hasta los 30 años y posteriormente, en grupos decenales. Entre las anotaciones que se realizaron en este impreso, los autores mencionaron que a partir de 1858 la población del naciente territorio había emprendido su crecimiento natural:

gracias a la sombra de la libertad del progreso y las reformas [...] Muchos emigrados vuelven a sus casa, se nota más animación, más movimiento [...] Así ve acrecentarse la población día a día y de un año a otro el aumento ha sido notable (Aznar y Carbó, 1861, pp. 126-127).

Sin embargo, en líneas posteriores veremos que esto no sucedió.

\section{VOLÚMENES DE POBLACIÓN, TASAS Y CURVAS DEMOGRÁFICAS}

Los criterios de Celia Maldonado (1995, pp. 44-46) en la ciudad de México fueron la base para obtener, por un lado, las cifras de población y, por el otro, las tasas de natalidad y mortalidad del puerto. En este caso, opté por los años que tuvieron las series completas de bautismos y defunciones, así como los registros de

\footnotetext{
${ }^{38}$ En el texto citado existe una descripción detallada del conflicto separatista, mientras que a escala nacional estalló la guerra de Reforma, enfrentamiento entre grupos liberales y conservadores de la república mexicana durante 1857 y 1860. Véase Galindo (1987).
}

población más cercanos a estos. En primer lugar, los informes estadísticos de 1814 fueron la principal referencia para el periodo de 1815 a 1821; se añadió la cantidad de nacimientos y la diferencia del total de defunciones. En segundo lugar, los reportes del Ayuntamiento para la población total en 1832. Así pues, los resultados entre 1829 y 1831 se obtuvieron con la resta de los nacimientos y la suma de las defunciones. Para finalizar, este procedimiento se repitió para los años de 1843 a 1858, y se eligió el conteo del censo de 1861. ${ }^{39}$

A continuación se calcularon las tasas de natalidad y mortalidad y se determinó la intensidad. ${ }^{40}$ Por último, se realizó un contraste con las cantidades de las ciudades de México y Guadalajara (Maldonado, 1995, pp. 100-105; Oliver, 1986, p. 69). En general, los resultados concuerdan con el patrón demográfico de la república mexicana durante el siglo XIX. Según el cuadro 3, las tasas aumentaron en 1848 a consecuencia de la guerra de Castas y la mortalidad fue mayor en 1855 a causa de la epidemia de viruela que se presentó en Yucatán. ${ }^{41}$ En las ciudades de México y Guadalajara, las enfermedades influían en el

${ }^{39}$ Se omitieron los guarismos posteriores a 1858 por razón del subregistro que encontramos en los libros parroquiales.

${ }^{40}$ Fórmula. Tasa de natalidad: (Total de nacimientos en un año/Población total $) \times 1000$. Tasa de mortalidad: (Total de fallecidos en un año/Población total $\times 1000$. En cuanto a la intensidad de la mortalidad, tasas de 0 a 15 bajas, de 16 a 29 moderadas y de 30 en adelante se infirieron como altas. Guía para la estimación de indicadores sociodemográficos (1996, pp. 15-16).

${ }^{41}$ En realidad, la mortalidad fue mayor durante la epidemia de cólera de 1833 pero no contamos con la información de los bautismos para ese año y la abordaremos más adelante. 


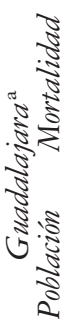

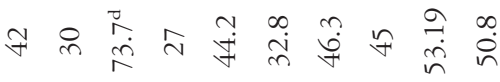

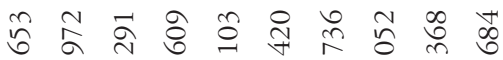

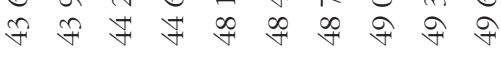

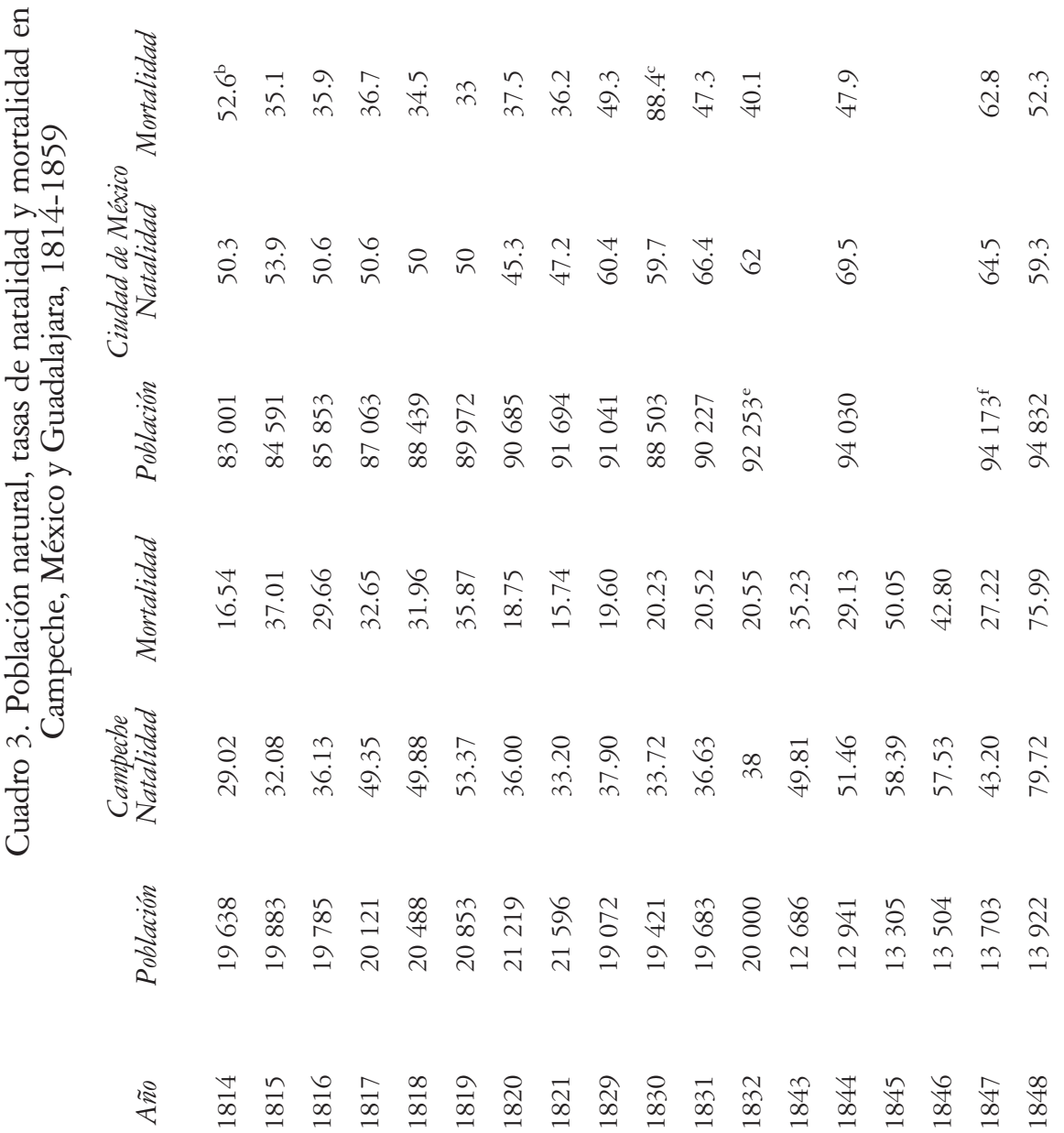

\section{(c) (1)}




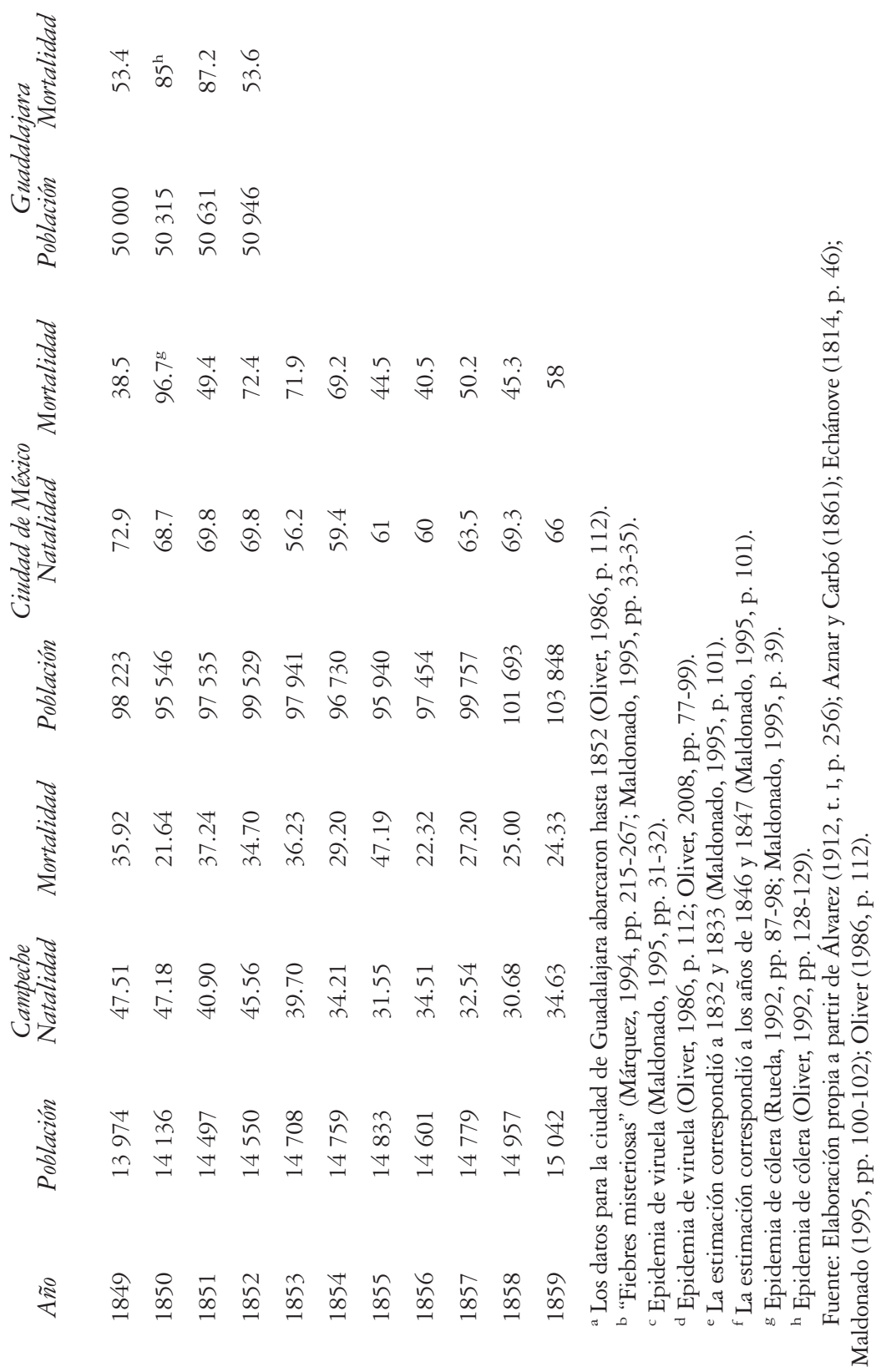

(ㄷ)(1) (5) 
incremento de las defunciones. ${ }^{42}$ En general, si comparamos las cantidades de las tres ciudades, esto responde al planteamiento inicial, tal como veremos a continuación.

\section{MORTALIDAD, NUPCIALIDAD Y NATALIDAD}

En este apartado analizaremos el comportamiento de las variables demográficas, así como la relación de estos indicadores con los volúmenes de población y los índices de crecimiento que se registraron en el puerto. Para la elaboración de las curvas demográficas ${ }^{43}$ me basé en los libros de bautizos, entierros y matrimonios correspondientes a las parroquias del Sagrario y San Francisco Extramuros, los cuales se encuentran en el Archivo Histórico de la Diócesis de Campeche. La parroquia del Sagrario comprendía el recinto amurallado o Plaza de Campeche, así como los barrios de Guadalupe, San Román y Santa Ana. Cabe señalar que en algunas ocasiones estos libros reportaron las actas del poblado de Lerma. A su vez, San Francisco Extramuros abarcó el suburbio del mismo nombre y Santa Lucía.

En relación con la parroquia del Sagrario las actas de entierros y bautizos están completas. Los libros de matrimonios presentaron lagunas de información en los barrios de Guadalupe, San Román y Santa Ana. ${ }^{44}$ En la parroquia de San Francisco Extramuros, la ausencia de datos es mayor en los tres indicadores y no fue posible especificar las correspondientes a cada barrio y, por lo tanto, se elaboró una

\footnotetext{
${ }^{42}$ Véanse las referencias señaladas en los cuadros.

43 Véanse las gráficas 1-6.

${ }^{44}$ Guadalupe: 1816-1823; San Román: 18191820, y Santa Ana: 1810, 1812-1817, 1820.
}

gráfica de esta zona. ${ }^{45}$ Además, es importante mencionar que a partir de 1823 no se identificó algún grupo étnico en todas las partidas.

Las actas de óbitos tenían los siguientes datos: nombre de la persona, sexo, casado o soltero, o viudos según fuera el caso, párvulos o adultos, el sitio donde fueron enterrados y el tipo de entierro. Las causas de los decesos se mencionaron únicamente durante la epidemia de viruela de 1855 . La edad apareció a partir de marzo de 1825, aunque de forma irregular y sólo en el caso de la parroquia del Sagrario. Para la epidemia de cólera de 1833 , los libros no registraron fallecimientos a partir del 24 de junio y se retomaron hasta los primeros días de agosto. Para completar las gráficas, se obtuvieron los datos de esta epidemia a partir de un cuadro estadístico elaborado en 1834.

La gráfica 1 contiene los datos de la ciudad de Campeche, y a pesar de las limitaciones que nos ofrecieron algunos libros, podemos realizar algunas consideraciones. En general, la mortalidad fue mayor en tres años (1815, 1833 y 1855), y la más importante está relacionada con la epidemia de cólera que en 1833 afectó a la ciudad. Los bautismos ${ }^{46}$ presentaron incrementos en coyunturas vinculadas a la escasez de alimentos y fenómenos migratorios por conflictos bélicos, lo cual demuestra que no tuvieron repercusión alguna en el crecimiento natural sostenido de la población. ${ }^{47}$

45 Bautizos: 1810-1813, 1833-1842; entierros: 1824-1828, 1860-1861; matrimonios: 1812, 1815-1816.

46 Para efectos de este trabajo los bautismos equivaldrán a los nacimientos.

${ }^{47}$ Me refiero a los años de 1817, 1818, 1819, 1827,1846 y 1848. 
Gráfica 1. Ciudad de Campeche, 1810-1861

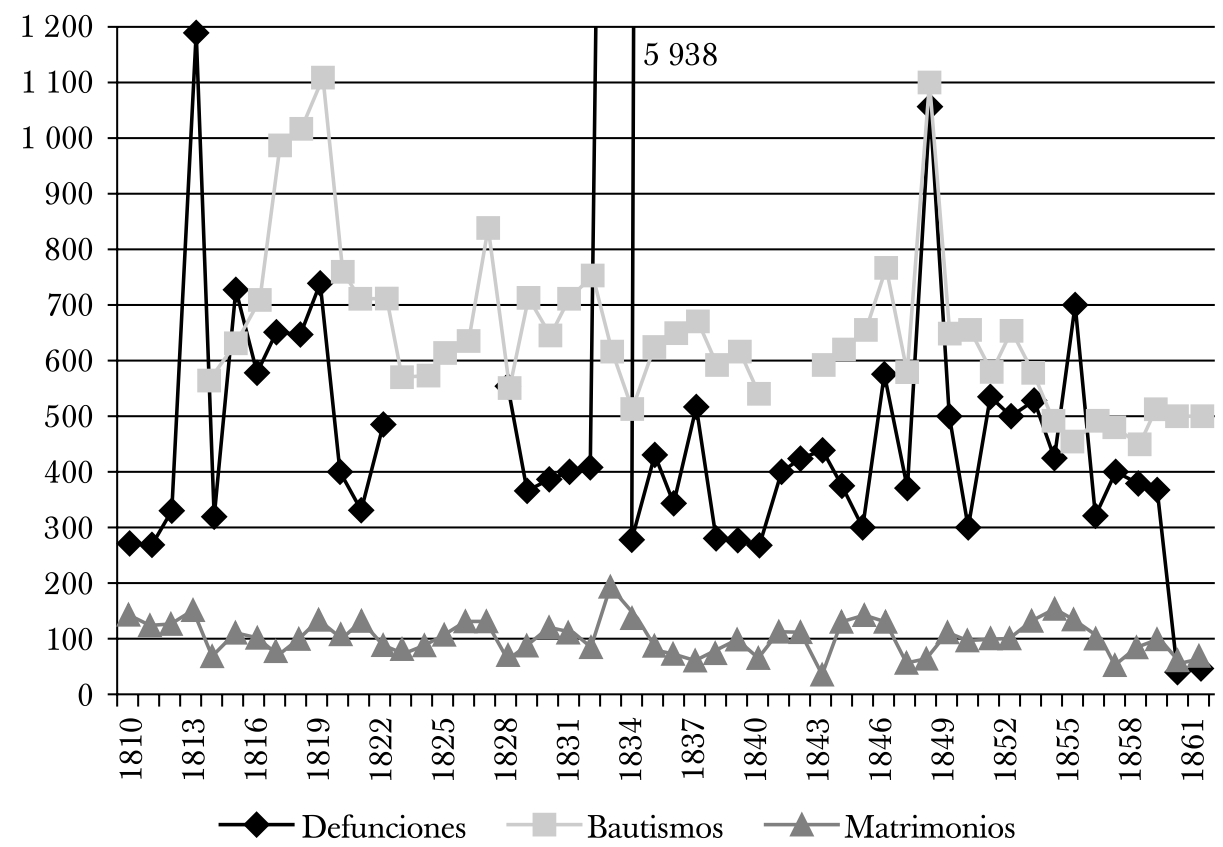

Fuente: libros de bautismos, defunciones y matrimonios. AHDC, México.

En 1853, el cólera fue, por segunda vez, motivo de preocupación por parte de las autoridades. Afortunadamente los resultados no fueron desastrosos en comparación con la primera epidemia. Entre 1854 y 1857 Yucatán sufrió los estragos de la viruela y las autoridades de la Junta Local de Sanidad del puerto tomaron las medidas preventivas correspondientes; ${ }^{48}$

${ }^{48}$ Otras entidades del país que resultaron afectadas durante ese periodo fueron: Chiapas, Oaxaca, Guerrero, Hidalgo y Zacatecas (Orvañanos, 1889, p. 147). También existieron reportes en Atlacomulco y en el Estado de México, donde en 1856 se reportaron 448 decesos por viruela (Molina, 2006, p. 154). pero en 1855 los libros de inhumaciones reportaron que $28.75 \%$ se debieron a este mal (Alcalá, 2008, p. 243). En este sentido, los resultados refuerzan las afirmaciones en relación con el papel preponderante de los padecimientos infecto-contagiosos en relación con los patrones demográficos del periodo en estudio.

En 1813,49 la mayor proporción de entierros se observó en el barrio de San Román (gráfica 4). Al parecer, esta situa-

${ }^{49}$ En 1813 el centro del país fue atacado por una serie de epidemias que han sido denominadas como de "fiebres misteriosas". Para la ciudad de México véase Márquez (1994, pp. 215-267). 
Gráfica 2. Plaza de Campeche, 1810-1861

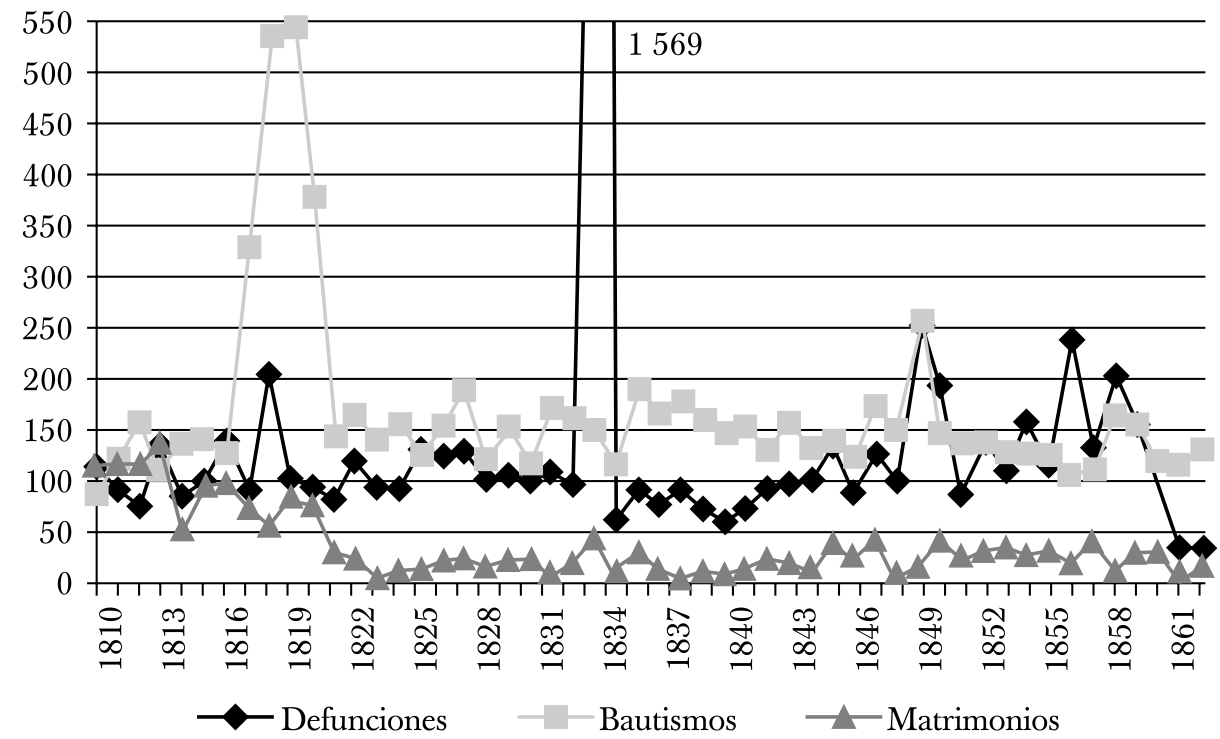

Fuente: libros de bautismos, defunciones y matrimonios. AHDC, México.

ción continuó hasta 1815 y las zonas más afectadas fueron las de Guadalupe, ${ }^{50}$ donde la mortalidad fue más significativa, y en Santa Ana (gráficas 3 y 5). En 1817, los datos señalan un aumento notable de recién nacidos en la plaza de Campeche (gráfica 2), en Guadalupe y San Román. Podría tratarse de un mecanismo compensatorio después de las epidemias de 1813 que al parecer afectaron a la ciudad, situación que deberá comprobarse con una investigación más exhaustiva. Mientras tanto, en Santa Ana, la mortalidad fue mayor en 1818 y en la parroquia de San Francisco Extramuros (gráfica 6) los dece-

${ }^{50}$ Desafortunadamente no contamos con los datos de bautismos. Aun así, el incremento de la mortalidad fue notable en comparación a otros años. sos fueron mayores entre 1815 y 1818 . En general, podemos constatar que la mortalidad está relacionada con las condiciones de vida y la distancia entre los barrios con respecto al centro de la ciudad.

Las variables que incidieron sobre los periodos de carestía y escasez de granos continuaron en la península de Yucatán entre 1820 y 1829 . Los resultados que se obtuvieron para la plaza de Campeche reflejaron las mejores condiciones y el rápido acceso tanto a los alimentos como a las disposiciones de la Junta de Sanidad. En general, las cifras de bautismos superaron las cifras de entierros, y en cuanto a los matrimonios, las cantidades descendieron en forma notable con respecto a la década anterior, situación debida al subregistro de las actas. La tendencia fue 
Gráfica 3. Barrio de Guadalupe, 1810-1861

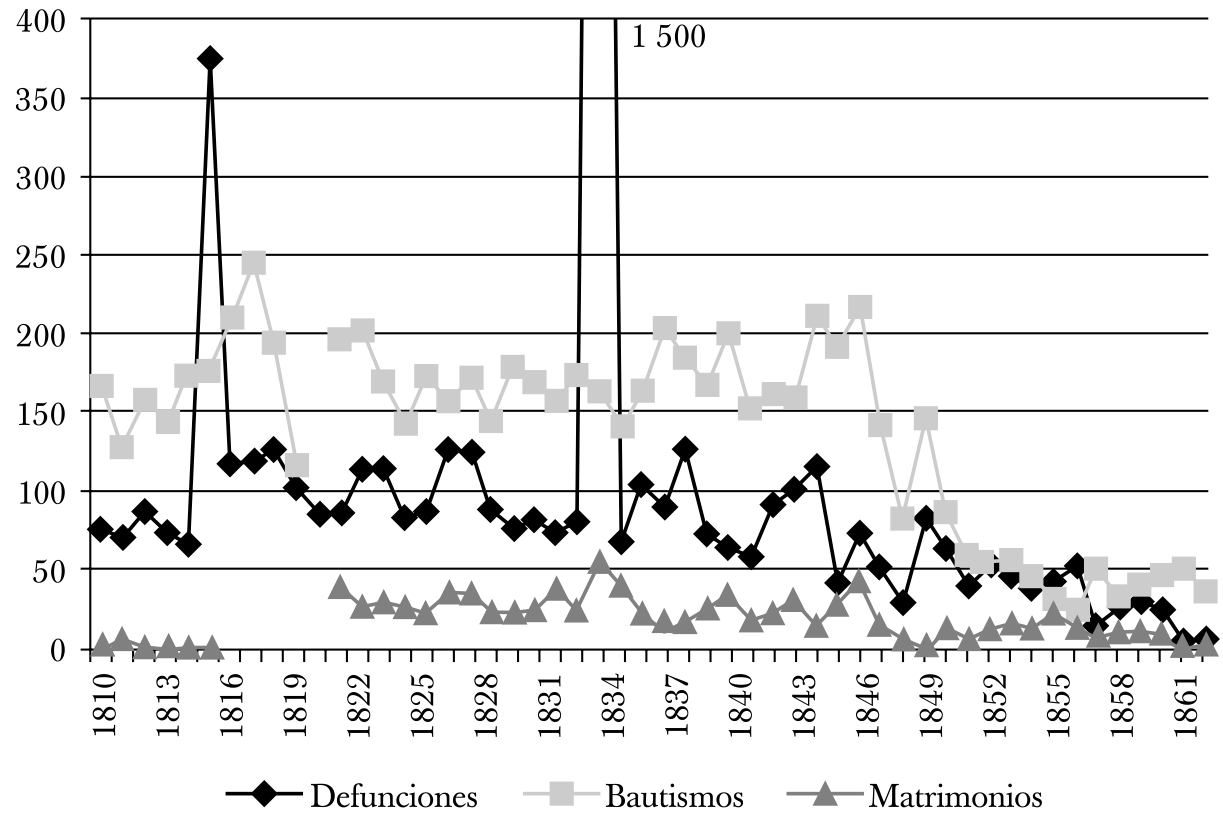

Fuente: libros de bautismos, defunciones y matrimonios. AHDC, México.

similar en el barrio de Guadalupe, a pesar de los incrementos en los entierros durante los años señalados en la gráfica correspondiente.

En San Román las cifras de mortalidad y natalidad fueron similares en 1821 y 1822, mientras que la primera variable fue mayor en 1826 y 1828. El suburbio de Santa Ana presentó cifras de entierros mayores a los bautismos en 1826 y 1827 , años en que las fuentes documentaron una epidemia de viruela. Por último, en San Francisco Extramuros la mortalidad fue mayor en 1828; desafortunadamente entre 1823 y 1827 la ausencia de cifras de este indicador no permitió establecer una tendencia. Al parecer, los periodos de hambre y epidemias no afectaron de manera importante a la ciudad durante este periodo; sin embargo, la mortalidad fue mayor en los barrios más pobres durante el brote de viruela.

La década siguiente presentó coyunturas de crisis importantes como la epidemia de cólera en 1833. De acuerdo con las investigaciones que se han realizado en México, esta enfermedad acabó con $10 \%$ de la población del país. Mientras tanto, algunas estimaciones para la península de Yucatán señalaron que esta "peste” aniquiló a más de 65000 personas. Según el reporte que solicitó el obispado de la entidad, la población adulta fue la más afectada y, en cuanto al sexo, los hombres presentaron las cifras más elevadas. Sin embargo, es importante señalar que estos 


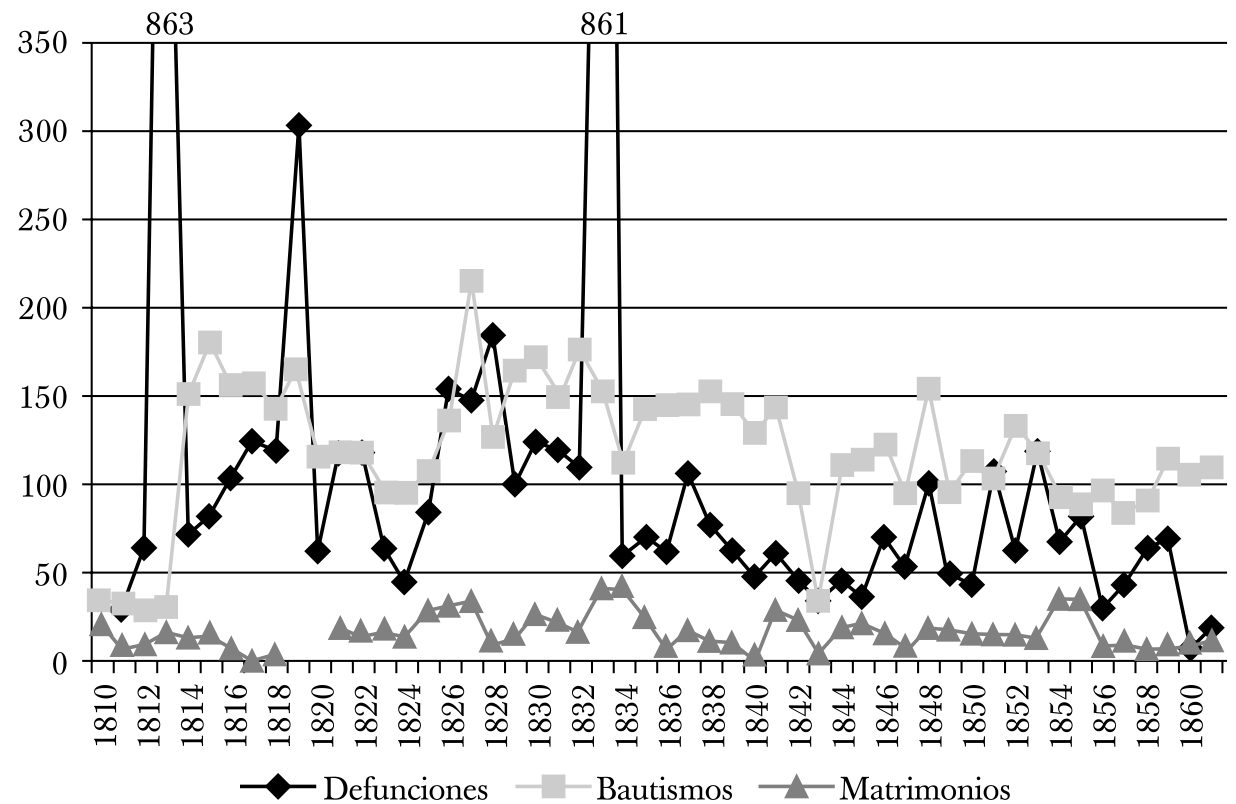

Fuente: libros de bautismos, defunciones y matrimonios. AHDC, México.

no mencionaron la edad en términos numéricos.

En Campeche, esta enfermedad acabó con $27.27 \%$ de la población, y en cuanto a la mortalidad por barrios tomé como referencia las cifras de población que se registraron en el censo de 1810. Esto se debió, en primer lugar, a que sus resultados son más confiables en comparación al de 1814 y, en segundo lugar, porque no existen estimaciones previas para los barrios del puerto. De acuerdo con este procedimiento, Guadalupe fue la zona más afectada porque $29.26 \%$ de su población falleció de cólera, mientras que el recinto amurallado fue la zona menos afectada. Esta situación demuestra una vez más cómo las zonas con mejores condiciones de vida y mayor acceso a los servicios públicos enfrentan mejor estas coyunturas.

Ante la magnitud de esta pandemia, las autoridades autorizaron la importación de harinas y maíz. Lamentablemente entre 1834 y 1835 la escasez de lluvias agravó la situación y la carestía de víveres produjo disturbios en la ciudad de Mérida, situación descrita por el viajero de origen austriaco Frederick de Waldeck. En el puerto, tal parece que su papel como intermediario para las actividades comerciales le permitió un adecuado abastacimiento de alimentos. En este sentido, las cifras de entierros retornaron a sus promedios habituales después de la epidemia.

Durante la década de 1840 podemos observar algunos cambios en las variables 
Gráfica 5. Barrio de Santa Ana, 1810-1861

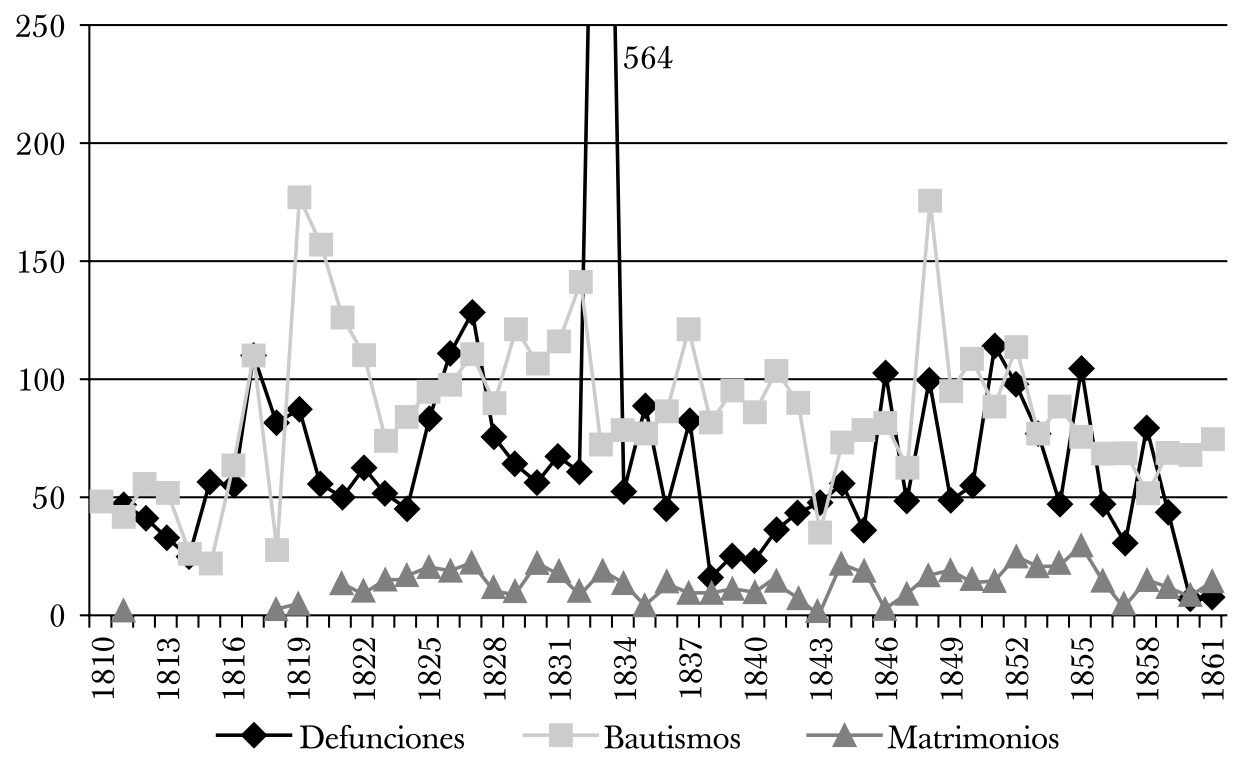

Fuente: libros de bautismos, defunciones y matrimonios. AHDC, México.

después del ataque que en 1843 sufrió el puerto por las tropas mexicanas. Los barrios de San Román y Santa Ana tuvieron mayor número de decesos, mientras que la zona amurallada tuvo un leve incremento de la mortalidad en 1844. Sin embargo, el evento con mayores efectos en la ciudad consistió en la inmigración por la guerra de Castas. Las gráficas muestran una fuerte concentración de entierros entre 1848 y 1849 , principalmente en la Plaza y los barrios de la parroquia de San Francisco Extramuros.

Posteriormente, las epidemias de cólera y viruela que se presentaron en 1853 y 1855 fueron los eventos que incidieron en las variables demográficas. Con respecto a la primera, aunque los registros parroquiales no señalan la causa del deceso, las gráficas señalaron que la mortalidad fue mayor en intramuros, Guadalupe y San Román. En cuanto a la segunda, solamente el barrio de San Román registró mayor cantidad de bautizos. Los matrimonios no resultaron un mecanismo compensatorio ante los incrementos de entierros durante los periodos coyunturales de crisis.

En 1855 se reportaron 700 decesos en los libros parroquiales, de los cuales $25.43 \%$ se debió a la viruela ${ }^{51}$ y el periodo de mayor incidencia fue durante mayo y agosto. A partir del mes de septiembre las cifras disminuyeron notablemente, pero la enfermedad afectó de manera importante a otros poblados de la penín-

\footnotetext{
${ }^{51}$ Las actas no señalan otras causas de muerte.
} 
Gráfica 6. Parroquia San Francisco (comprende el barrio de San Francisco y Santa Lucía), 1810-1861.

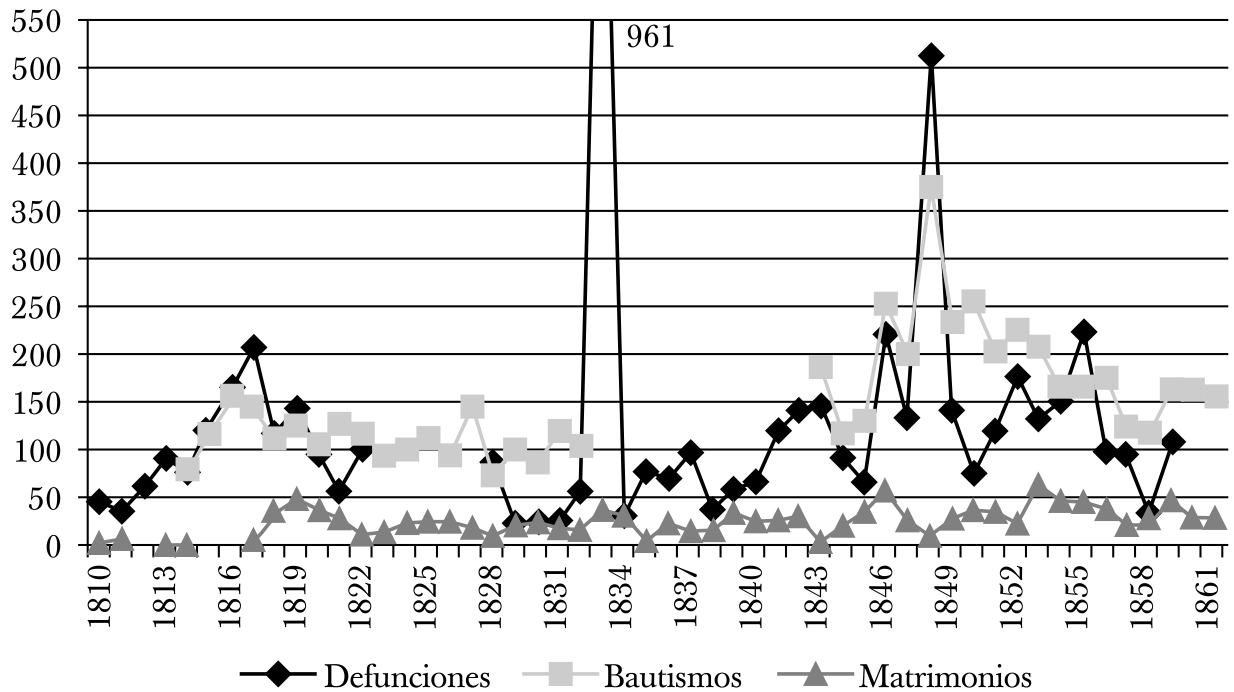

Fuente: libros de bautismos, defunciones y matrimonios de la parroquia San Francisco. AHDC, México.

sula y, de acuerdo con Erosa (1993), esta epidemia produjo la muerte de casi 20000 personas entre 1854 y 1857 : "constituyendo una verdadera catástrofe para los habitantes de Yucatán, pues hizo desaparecer familias enteras, prolongándose hasta mediados de 1857" (p. 57).

En resumen, tal como lo señalaron algunos intelectuales de la época como Justo Sierra O’ Reilly, después de la guerra de Castas la ciudad de Campeche entró en una fase de contracción de las actividades económicas y gran parte de sus habitantes emigraron hacia otros lugares, como la ciudad de Mérida. En esta coyuntura, la separación del distrito campechano escindió a la península en dos entidades. Se hicieron propuestas para el crecimiento económico del naciente territorio y el objetivo se dirigió hacia la agricultura, pero en 1898 la prensa señalaba que la población del estado de Campeche se había reducido a menos de la mitad y que las causas más ostensibles habían sido el cólera de 1833 y 1853 , así como la guerra social que tuvo lugar en los años de 1846 a $1849 . .^{52}$

En general, podemos señalar que durante los años de 1810 y 1832, los reportes de las estimaciones indican que la ciudad tenía 20000 habitantes y que esa cifra no presentó cambios significativos debido a los índices elevados de natali-

${ }^{52}$ Este dato pertenece a un artículo intitulado "Repoblación del estado", La Aspiración del Estado, año IV, núm. 36, 13 de noviembre de 1898 y reproducido en Negrín (1991, t. I, pp. 295-297). 
dad. En cuanto al crecimiento natural de la población, los cuadros 2 y 3 muestran que los índices de mortalidad solamente fueron mayores en 1815, situación que también se refleja en las gráficas. En este sentido, las crisis alimentarias y las epidemias que se reportaron para este periodo no afectaron el comportamiento demográfico del puerto. Sin embargo, existe una mortalidad diferenciada en algunos barrios como Santa Ana, San Francisco y Santa Lucía, cuyas cifras de mortalidad en algunas coyunturas fueron mayores, debido a las condiciones de vida que prevalecían en esas zonas.

Entre 1833 y 1861 se encuentran algunos eventos que algunos pensadores de la época han considerado como la decadencia del puerto de Campeche y su decremento poblacional. La epidemia de cólera que en 1833 afectó a la república mexicana tuvo importantes repercusiones en la ciudad. Las estimaciones que se realizaron en relación con el número de fallecidos y la población total mostraron un decremento del crecimiento demográfico; aspecto que también es notorio en las gráficas por la relación de entierros con bautizos. Posteriormente, las cifras de estas variables retomaron la tendencia del periodo anterior, con un crecimiento natural lento, pero sostenido. El problema consiste en que las cuentas posteriores insistieron con una cifra de 15000 habitantes.

Los siguientes acontecimientos no alteraron el crecimiento natural de la población. En 1848, la migración masiva de refugiados por la guerra de Castas presentó incrementos en las tasas de mortalidad y natalidad en comparación con los años previos, aspecto que también se muestra en las curvas de las variables demográficas. Mientras que la epide- mia de viruela de 1855 fue el tercer evento que manifestó mayores cifras de entierros que bautizos y que puede observarse tanto en los cuadros como en las gráficas. Los intelectuales de la época señalaron que la epidemia de cólera y la emigración después de la guerra de Castas contribuyó a la decadencia económica y la disminución del número de habitantes de la localidad. En este caso tendremos que considerar los factores migratorios como una variable a desarrollar en futuras investigaciones y que profundicen en las variaciones demográficas que sufrió el puerto campechano durante este periodo.

\section{CONCLUSIONES}

En primer lugar, la población del puerto fue calculada con base en dos valoraciones. La primera entre 18000 y 20000 habitantes entre 1810 y antes de la epidemia de cólera de 1833. La segunda fue de 15000 personas, cifra que se manejó hasta principios de siglo $\mathrm{xx}$ y fue un punto de inflexión en el crecimiento de la población local.

En segundo, algunas crisis agrícolas y la guerra de Castas propiciaron que el puerto se convirtiera en un punto de refugio de la población indígena, cuya gran mayoría se concentró en los barrios extramuros, mientras que la población blanca estuvo en el recinto amurallado. En este sentido, hay que señalar la necesidad de mayores estudios para las crisis agrícolas que se presentaron en la primera mitad del siglo XIX, principalmente entre 1810 y 1827 , debido a los aumentos de la mortalidad y natalidad para ese periodo.

En tercero, Cook y Borah (1977, t. II) mencionaron que la población de Yucatán 
experimentó un crecimiento sostenido entre 1750 y 1840. Sin embargo, ellos afirmaron que "después de 1840, la población empezó a detenerse” (p. 133). En este punto, habría que destacar dos aspectos: En primer lugar, este periodo se caracterizó por una serie de enfrentamientos armados que se presentaron en la península (véase Campos, 2002) y sería interesante un análisis de las consecuencias demográficas para corroborar esta aseveración; en segundo lugar, habría que considerar si esta disminución se presentó a partir de la epidemia de cólera en 1833 y que según algunos estudiosos del tema acabó con $10 \%$ de la población de la entidad (Malvido, 2006, p. 150).

En cuarto, el crecimiento natural de la población del puerto durante los años que no se presentaron coyunturas de crisis fue lento y los indicadores de natalidad y mortalidad fueron elevados, lo cual confirma los planteamientos de Victoria Lerner, Robert Mc Caa y Celia Maldonado en relación con el patrón demográfico que se presentó en México durante el siglo XIX.

Quinto, con respecto a las curvas de los indicadores demográficos, las fuentes destacaron que las epidemias de cólera de 1833 y la viruela de 1855 fueron las enfermedades que más afectaron a la ciudad. En cuanto a otros eventos, los fenómenos migratorios como el de 1848 fueron considerados por los intelectuales de la época como una de las causas en el descenso de la población y la decadencia del puerto. Las gráficas por barrio demuestran que las condiciones de vida se convirtieron en factores predisponentes para los elevados índices de mortalidad, que en algunos años superaron a los nacimientos, principalmente entre 1810 y 1827 , años relacionados con crisis de subsistencia. Por otra parte, la curva de matrimonios no tuvo oscilaciones que indicaran algún tipo de mecanismo compensatorio.

Para finalizar, considero que la principal aportación de este trabajo consiste en un primer ejercicio para explicar la relación entre diversos acontecimientos que influyeron en las variables demográficas de Campeche, así como las dificultades que presentan las fuentes relacionadas con los estudios de población. En este punto, esto responde a la necesidad que han planteado diversos investigadores en relación con los estudios locales. Reduciendo la escala de observación, sería interesante el estudio individualizado de estos fenómenos para un mayor análisis de la dinámica poblacional de esta localidad.

\section{REFERENCIAS}

-Aguayo, M. y Cahuich, G. (1997). La feria de San Román: Reflejo de una mentalidad colectiva, 1565-1997. Campeche: Gobierno del Estado.

-Alcalá, C. (2008). Asistencia, sanidad y población en la ciudad de San Francisco de Campeche, 1812-1861. (Tesis doctoral inédita). Universidad de Barcelona, Barcelona.

-Alcalá, C. (2010). La ciudad de Campeche a través de viajeros extranjeros, 1834-1849. Relaciones, XXXI(122), 201-244.

-Álvarez, F. (1912). Anales históricos de Campeche (t. I). Campeche: Imprenta del Editor.

-Arjona, M. (2007). Organización territorial de la ciudad de San Francisco de Campeche en el siglo XVIII. (Tesis de maestría inédita). Universidad Autónoma de Yucatán, Mérida.

-Aznar, T. y Carbó, J. (1861). Memoria sobre la conveniencia, utilidad y necesidad de erigir constitucionalmente en estado de la confederación mexicana el antiguo distrito de Campeche. Constituido de becho en Estado Libre y Soberano desde mayo de 1848 por 
virtud de los convenios de división territorial que celebró con el estado de Yucatán, de que era parte. México: Imprenta de Ignacio Pulido.

-Berzunza, R. (1965). Guerra social en Yucatán. Campeche: Gobierno del Estado.

-Calvo, T. (1973). Acatzingo. Demografía de una parroquia mexicana. México: Instituto Nacional de Antropología e Historia.

-Calzadilla, J., Bolio, P. y Zuaznávar, J. (1977 [1871]). Apuntaciones para la estadística de la provincia de Yucatán. Mérida: Gobierno del Estado.

-Campos, M. (2002). Que los yucatecos todos proclamen su independencia. Mérida: Universidad Autónoma de Yucatán.

-Campos, M. (ed.) (2006). Entornos del ciudadanato en Yucatán, 1750-1906. Mérida: Universidad Autónoma de Yucatán.

-Castillo, J. (2002). La pobreza en Yucatán. Ideas, instituciones y prácticas sociales, 1786-1856. (Tesis doctoral). El Colegio de México.

-Cline, H. (1945). War of the castes ind its consequences. Related studies in early nineteenth century Yucatecan social history (microfilm, 23). Chicago.

-Contreras, A. (2009). Movimientos migratorios hacia el oriente de Yucatán (1750-1825). En Ch. Cramaussel (ed.), Demografía y poblamiento del territorio: La Nueva España y México, siglos XVI-XIX (pp. 81-92). Zamora: El Colegio de Michoacán.

-Cook, S. y Borah, W. (1977). Ensayos sobre historia de la población. México y el Caribe (t. II). México: Siglo XXI Editores.

-Cuenya, M. (1999). Puebla de los Ángeles en tiempos de una peste colonial: una mirada en torno al matlazabuatl de 1737. Zamora: El Colegio de Michoacán/Benemérita Universidad Autónoma de Puebla.

-Cuenya, M. y Malvido E. (1992). La pandemia de cólera de 1833 en la ciudad de Puebla. En M. Cuenya, E. Malvido, C. Lugo, A. Carrillo y L. Oliver Sánchez. El cólera de 1833. Una nueva patología en México. Causas y efectos (pp. 11-45). México: Instituto Nacional de Antropología e Historia.

-Dumond, D. (2005). El machete y la cruz: la sublevación de campesinos en Yucatán. México: Universidad Nacional Autónoma de México.

-Echánove, P. (1814). Cuadro estadístico de Yucatán en 1814. Mérida: Imprenta del Editor.

-Enciclopedia yucatanense (1944), Mérida, Gobierno del Estado.

-Escobar Ohmstede, A. (2004). Desastres agrícolas en México. Catálogo histórico (t. II.). México: FCE/CIESAS.

-Erosa, A. (1993). Monografía sobre salud pública en Yucatán. Mérida: Servicios Coordinados de Salud Pública.

-Falla, M. (2009). La epidemia de 1782 en Izamal. En Ch. Cramaussel (ed.), Demografía y poblamiento del territorio: La Nueva España y México, siglos XVI-XIX (pp. 217-225). Zamora: El Colegio de Michoacán.

-Farriss N. (1984). La sociedad maya bajo el dominio colonial. Una empresa colectiva de supervivencia. Madrid: Alianza Editorial.

-Galindo, M. (1987). La gran década nacional, 1857-1867 (3 vols.). México: INERHM.

-García, M. (1978). Población y encomienda en Yucatán bajo los Austrias. Sevilla: Consejo Superior de Investigaciones Científicas.

-García, J. (1846). Memoria leída ante el Augusto Congreso Extraordinario de Yucatán por el secretario general de Gobierno, el día 18 de septiembre de 1846. Mérida: Imprenta de Castillo y Compañía.

-García, V., Pérez, J. y Molina, A. (2003). Desastres agrícolas en México. Catálogo histórico (t. I). México: FCE/CIESAS.

-Goubert, P. (1960): Beawvais et la Beanvaisis de 1600 à 1730. París: SEVPEN.

-Guerra, F. (1999). El soberano y su reino. Reflexiones sobre la génesis del ciudadano en América Latina. En H. Sabato (ed.), Ciudadanía politica y formación de las naciones. Perspectivas his- 
tóricas de América Latina (pp. 33-61). México: FCE.

- Guía para la estimación de indicadores sociodemográficos (1996). México: Consejo Nacional de Población.

-Heller, C. (1987 [1853]). Viajes por México en los años 1845-1848. México: Banco de México.

-Laviada, F. (1993). El cólera en la península de Yucatán en el siglo pasado. Revista Biomédica, 1, 43-48.

-Lerner, V. (1968). Consideraciones sobre la población de la Nueva España (1793-1810) según Humboldt y Navarro y Noriega. Historia Mexicana, 17(3), 327-348.

-Mc Caa, R. (1993). El poblamiento del México decimonónico: escrutinio crítico de un siglo censurado. En El poblamiento de México. Una visión histórico-demográfica. México en el siglo XIX (pp. 90-114). México: Secretaría de Gobernación/CONAPO/Grupo Azabache.

-Maldonado, C. (1995). Ciudad de México, 1800-1860: epidemias y población. México: Instituto Nacional de Antropología e Historia.

-Malvido, E. (1973). Factores de despoblación y de reposición de la población de Cholula (1641-1810). Historia Mexicana, XXIII(1), 52-110.

-Malvido, E. (2006). La población, siglos XVI al Xx. México: Océano.

-Márquez, L. (1994). La desigualdad ante la muerte de la ciudad de México. El tifo y el cólera. México: Siglo XXI Editores.

-Meuvret, J. (2003 [1946]). La crisis de subsistencia y la demografía en la Francia de antiguo régimen (tr. Pedro Canales). Contribuciones desde Coatepec, III(5), 131-140.

-Molina, A. (2006). Comportamiento y distribución de la población en Santa María de Guadalupe, Atlacomulco, 1679-1860. En A. Molina y D. Navarrete (coords.), Problemas demográficos vistos desde la bistoria: análisis de fuentes, comportamiento y distribución de la población de México, siglos XVI-XIX (pp. 117-154). Zamora: El Colegio de México/ El Colegio de Michoacán.
-Molina, R. (1941). Las hambres en Yucatán. México: Orientaciones.

-Morelet, A. (1871). Travels in Central America. Nueva York: Leopoldt, Hold and Williams.

-Morin, C. (1973). Santa Inés de Zacatelco, 1646-1812. Contribución a la demografía bistórica del México colonial. México: Instituto Nacional de Antropología e Historia.

-Muñoz, L. (2006). Barcos, bultos y pasajeros en los puertos del Golfo: Los primeros años del México independiente. En J. von Grafenstein (coord.), El Golfo-Caribe y sus puertos. 1600-1850 (t. I, pp. 469-514). México: Instituto Mora.

-Negrín, A. (1991). Campeche. Una bistoria compartida. México: Instituto Mora.

-Norman, B. (1843). Rambles in Yucatan (2a. ed.). Nueva York: J. \& H. Langley.

-O'Gorman, E. (1966). Historia de las divisiones territoriales de México (3a. ed.). México: Editorial Porrúa (xolección "Sepan Cuantos...”, 45).

-Oliver, L. (1986). Un verano mortal. Guadalajara: Gobierno del Estado de Jalisco.

-Oliver, L. (1992). La mortalidad, 18001850. En J. Muriá y J. Olveda (coords.), Demografía y urbanismo, lecciones históricas de Guadalajara (t. III, pp. 101-137). México: Instituto Nacional de Antropología e Historia.

-Oliver, L. (2008). La epidemia de viruela de 1830 en Guadalajara. Relaciones, XXIX(114), 77-99.

-Orvañanos, D. (1889). Ensayo de geografía médica y climatología de la república mexicana. México: Secretaría de Fomento.

-Parrish, W. (1853). A visit to Mexico, by The West India Islands, Yucatan and United States, with observations and adventures on the map (vol. I). Londres: Publisher by the autor.

-Peniche, P. (2010). Tiempos aciagos: las calamidades y el cambio social del siglo XVIII entre los mayas de Yucatán. México: CIESAS/Porrúa.

-Pérez-Mallaína, P. (1978). Comercio y autonomía en la Intendencia de Yucatán. 1797-1814. Sevilla: Escuela de Estudios Hispanoamericanos. 
-Pérez, V. (1980). Las crisis de mortalidad en la España interior. Siglos XVI-XIX, Madrid: Siglo XXI Editores.

-Rabell, C. (1990). La población novobispana a la luz de los registros parroquiales. (Avances y perspectivas de investigación). México: UNAM (Cuadernos de Investigación, núm. 21).

-Ramayo, T. (1996). Los mayas pacíficos de Campeche. Campeche: Universidad Autónoma de Campeche.

-Ramos, M. (1875). El agua. Ensayos hidrotimétricos de las aguas de los pozos de Belén y el Mamey. La Alborada, 7, 186-192.

-Reed, N. (1985 [1964]). La guerra de Castas de Yucatán (7a. ed.). México: Biblioteca Era.

-Regil, J. (1853). Estadística de Yucatán. México: Sociedad Mexicana de Geografía y Estadística.

-Rodríguez Herrera, E. (2010). Campeche e identidad en el discurso de la memoria (Tesis de maestría inédita). Universidad Autónoma Metropolitana-Unidad Azcapotzalco, México.

-Rodríguez, S. (1985). Geografía politica de Yucatán. Censo inédito de 1821. Año de la Independencia (t. I.). Mérida: Universidad Autónoma de Yucatán.

-Rodríguez, S. (1989). Geografía política de Yucatán. División territorial, gobierno de los pueblos y población 1821-1900 (t. II). Mérida: Universidad Autónoma de Yucatán.

-Rueda, S. (1992). El viajero funesto. El cólera morbus en la ciudad de México, 1850. Historias, 28, 87-98.

-Rubio, I. (1942). Archivo de la Historia de Yucatán. Campeche y Tabasco, México: Imprenta Aldina, Robredo y Rosell.

-Sánchez, N. (1973). La población de América Latina: Desde los tiempos precolombinos al año 2000. Madrid: Alianza Editorial.

-Sierra, C. (1975). Campeche. Imagen de una ciudad. México: Publicaciones Históricas.

-Sierra O’ Reilly. J. (1991 [1853]). Prosperidad y decadencia en Campeche. En A. Negrín (comp.), Campeche. Textos de su historia (t. I, pp. 23-31). México: Gobierno del Estado de Campeche/Instituto Mora.

-Stephens, J. (1986 [1843]). Viajes a Yucatán (2 tt.). Mérida: Consejo editorial de Yucatán.

-Tena, F. (1999). Leyes fundamentales de México. 1808-1999 (22a. ed.). México: Porrúa.

-Trujillo, M. (2005). El Golfo de México en la centuria decimonónica: entornos geográficos, formación portuaria y configuración marítima. México: CIESAS.

-Urías, M. y San Juan, C. (1982). Población y desarrollo en el México del siglo XIX. Investigación Económica, 162, 129-177.

-Villalobos, M. (2006), El bosque sitiado: asaltos armados, concesiones forestales y estrategias de resistencia durante la guerra de Castas. México: CIESAS.

-Waldeck, F. (1996[1837]). Viaje pintoresco y arqueológico a la provincia de Yucatán, 1834 y 1836. México: Consejo Nacional para la Cultura y las Artes.

\section{OTRAS FUENTES}

\section{Archivos}

AGEY Archivo General del Estado de Yucatán. AMCA Archivo Municipal de Campeche.

AGEC Archivo General del Estado de Campeche.

AHDC Archivo Histórico de la Diócesis de Campeche.

\section{Bibliografía}

-Osorio, R. (1944). Historia de la medicina alopática en la época independiente. En Enciclopedia yucatanense, (t. IV, pp. 258-341). Mérida: Gobierno del Estado.

-Rubio, M. y Tzuc, L. (1995). 24 horas para morir: epidemia del cólera morbo en Yucatán, 1833. Revista Biomédica, 2, 102-107. 